\title{
Role of corticosteroids in Functional Endoscopic Sinus Surgery - a systematic review and meta-analysis*
}

\author{
Vishal Pundir ${ }^{1}$, Jyotsna Pundir², Gillian Lancaster ${ }^{3}$, Simon Baer ${ }^{4}$, Paul Rhinology 54:3-19, 2016 \\ Kirkland ${ }^{4}$, Marjolein Cornet', E.S. Lourijsen' ${ }^{1}$ Christos Georgalas' ${ }^{1}$, W.J. Fokkens ${ }^{1}$ Do:10.4193/Rhino15.079 \\ ' Ear Nose and Throat Department, Academic Medical Centre, Amsterdam, the Netherlands \\ *Received for publication: \\ 2 Department of Obstetrics and Gynaecology, Barts Health NHS Trust, United Kingdom \\ March 24, 2015 \\ ${ }^{3}$ Department of Mathematics and Statistics, Fylde College, Lancaster University, Lancaster, United Kingdom \\ Accepted: May 25, 2015
}

\begin{abstract}
Background: The aim of our study is to systematically review the existing evidence on the role of corticosteroids in patients undergoing functional endoscopic sinus surgery (FESS).
\end{abstract}

Methodology: Systematic search of MEDLINE (1950- 2014), EMBASE (1980-2014), metaRegister, Cochrane Library and ISI conference proceedings was carried out.

Results: Eighteen randomised controlled trials with 1309 patients were included. Use of local and/or systemic corticosteroids with FESS was reported in four categories; operative, anaesthesia related, post-operative outcomes and risk of recurrence. Metaanalysis for operative outcomes demonstrated that, mean operative time (MD -10.70 minutes; $95 \% \mathrm{Cl}-15.86,-5.55 ; \mathrm{P}<0.0001$ ) and mean estimated blood loss (MD $-28.32 \mathrm{mls} ; 95 \% \mathrm{Cl}-40.93,-15.72 ; \mathrm{P}<0.0001$ ) was significantly lower; and surgical field quality (MD - $0.81 ; 95 \% \mathrm{Cl}-1.32,-0.30 ; \mathrm{P}=0.002$ ) was significantly better in corticosteroid group. Meta-analysis showed that post-operative endoscopic scores (SMD $-0.39 ; 95 \% \mathrm{Cl}-0.60,-0.17 ; \mathrm{P}=0.0004$ ) were significantly better in corticosteroid group compared to no corticosteroid group. There was no increase in risk of sinusitis ( $R R 0.64 ; 95 \% \mathrm{Cl} 0.32,1.30 ; \mathrm{P}=0.22$ ) between use of corticosteroids and no corticosteroids; There was no significant difference in recurrence risk of chronic rhinosinusitis (CRS) in mixed population studies (RR $0.77 ; 95 \% \mathrm{Cl} 0.35,1.70 ; \mathrm{P}=0.52$ ) between the two groups but analysis of studies reporting on chronic rhinosinusitis with nasal polyps (CRSwNP) (RR 0.64;95\% $\mathrm{Cl} 0.45,0.91 ; \mathrm{P}=0.01$ ) showed significant difference in favour of the corticosteroid group.

Conclusion: Pre-operative use of local and/or systemic corticosteroids in FESS, results in significantly reduced blood loss, shorter operative time and improved surgical field quality. Studies are limited on the intra-operative use of corticosteroids to reduce postoperative pain. Postoperative corticosteroids improve postoperative endoscopic scores in CRS and recurrence rates in cases of CRSWNP.

Key words: Functional Endoscopic Sinus Surgery, FESS, chronic rhinosinusitis, corticosteroids

\section{Introduction}

Chronic rhinosinusitis (CRS) is a common disabling condition resulting in significant healthcare cost and loss in productivity. The prevalence rate of CRS have been quoted from $5.5 \%$ in South America, $10.9 \%$ in Europe to about $16 \%$ in America ${ }^{(1-3)}$. CRS (including CRS with nasal polyps(CRSwNP)) is defined by European position paper on rhinosinusitis and nasal polyps (EPOS 2012), as "inflammation of the nose and the paranasal sinuses cha- racterised by two or more symptoms, one of which should be either nasal blockage/obstruction/congestion or nasal discharge (anterior/posterior nasal drip), \pm facial pain/pressure, \pm reduction or loss of smell; and either endoscopic signs of polyps and/ or mucopurulent discharge primarily from middle meatus and/ or; oedema/mucosal obstruction primarily in middle meatus, and/or CT changes showing mucosal changes within the osteomeatal complex and/or sinuses"(4). Rhinosinusitis (RS) can 
be acute when symptoms or signs subside within 12 weeks and chronic (CRS) if these persist for more than 12 weeks ${ }^{(4)}$. CRS can be with or without nasal polyps (CRSwNP, CRSsNP) and affects $2-16 \%{ }^{(5,6)}$ and $2-3 \%{ }^{(4,7)}$ of the population, respectively. CRS is considered as a multifactorial disease. Environmental factors include pollution, smoking, fungus, bacterial and viral infections. Host factors can be general factors like immune deficiencies and genetic factors, and local host factors causing persistent focal inflammation within the ostiomeatal complex ${ }^{(8)}$. Initial therapy for CRS includes nasal saline irrigation, topical and systemic corticosteroids, and in cases of CRSsNP potentially long term antibiotics followed by surgical intervention in unresponsive patients ${ }^{(4,6)}$. Corticosteroids reduce nasal mucosal inflammation and therefore increase drainage of infected mucosal secretions and aid the healing process.

Patients who fail to respond to medical therapy are considered for functional endoscopic sinus surgery (FESS), which is one of the most common surgical procedures performed ${ }^{(5,9)}$. Endoscopic sinus surgery was described by Stammberger ${ }^{(10)}$ in 1985 and Kennedy ${ }^{(11)}$ coined the term FESS to highlight its surgical philosophy of mucosal sparing. About $80 \%$ of patients have successful outcome but $20 \%$ patients suffer from relapse of sinusitis or complications warranting further surgical intervention ${ }^{(12)}$.

Corticosteroids have been used preoperatively, intraoperatively and postoperatively in FESS for rhinosinusitis. FESS creates a conduit for topical steroids to reach the deeper part of the sinus cavity and act on the mucosa which was previously inaccessible. Intranasal corticosteroids are therefore often included in postoperative treatment regimens. Both local and systemic corticosteroids have also been used preoperatively to reduce inflammation and intraoperative bleeding, thereby improving surgical field ${ }^{(13,14)}$. It has also been shown that asthmatic patients who are given corticosteroids preoperatively have low incidence of pulmonary complications in the perioperative time period ${ }^{(15)}$. Corticosteroids have also been postulated in pain control when used intraoperatively ${ }^{(16)}$. There are several randomised controlled trials evaluating the role of corticosteroids in FESS, however, these studies have reported conflicting results.

The aim of our study was to systematically review the existing evidence on the role of corticosteroids in patients with CRS undergoing FESS. The aim was to determine whether preoperative corticosteroids affect operative parameters; intra-operative corticosteroids reduce surgical pain; and postoperative corticosteroids affect patient's symptom scores, endoscopic appearance and recurrence rates.

\section{Methods}

Data sources and literature search
We conducted systematic searches for randomised controlled trials (RCTs). There were no language, publication year or publication status restrictions. The date of the last search was 20.09.2014. We searched MEDLINE, EMBASE, Web of science, metaRegister, Cochrane Library and ISI conference proceedings. A combination of $\mathrm{MeSH}$ and text words were used to generate two subsets of citations, one including studies of endoscopic surgery ('endoscopic sinus surgery', 'endoscopic polypectomy', 'FESS', 'functional endoscopic sinus surgery') and the second including corticosteroids ('corticosteroids', 'steroids,' 'corticoids', 'dexamethasone,',fluticasone,' 'budesonide,',mometasone, , prednisone", "prednisolone", "beclomethasone", "triamcinolone"). These subsets were combined using 'AND' to generate a subset of citations relevant to our research question. The reference lists of all known primary and review articles were hand searched to identify cited articles not captured by electronic searches. The searches were conducted independently by VP and JP.

\section{Study selection}

Two review authors (VP and JP) performed data selection and extraction based on predetermined criteria. Studies were selected in a two-stage process. Firstly, the titles and abstracts from the electronic searches were scrutinized and full manuscripts of all citations that were likely to meet the predefined selection criteria were obtained. Final inclusion or exclusion decisions were made on examination of the full manuscripts. In cases of duplicate publication, the most recent or complete versions were selected. We documented our justification for the exclusion of studies.

\section{Data extraction}

Two reviewers (JP and VP) completed data extraction. Study characteristics and participant features were extracted from each study regarding: characteristics of trials - setting, design, method of data analysis; participants - study population, number of participants; type of intervention: dose, route of administration, duration of treatment, follow-up and outcomes. Inconsistencies between reviewer's data were resolved through discussion with a third reviewer (SB) until a consensus was reached. After identifying the studies where additional data were needed, a request was sent by means of electronic mail to the corresponding author of each study. If no response was received, a second request was sent 2 weeks later by means of electronic mail.

\section{Data synthesis \\ Inclusion and exclusion criteria}

Studies were selected if the target population underwent FESS, and were exposed to corticosteroids and compared with either placebo or no corticosteroids. Only RCTs were included. Trials which included participants of any age, who had any co-morbidity including asthma and aspirin sensitivity, allergic or non- 
allergic, followed for any duration and CRS with and without polyps were included. Studies were excluded if the patients had taken corticosteroids in the absence of FESS.

\section{Outcomes assessed}

The outcomes were assessed under four categories. Operative outcomes, anaesthetic related outcomes, post-operative outcomes and risk of recurrence. Operative outcomes included estimated blood loss (EBL), surgical field quality and operative time. Postoperative outcomes included symptoms score (subjective improvement), endoscopic score (objective improvement) and risk of sinusitis.

\section{Assessment of risk of bias in included studies}

We assessed the methodological quality of the included studies and carried out the assessment of risk of bias taking into consideration: method of randomisation; allocation concealment; blinding; incomplete outcome data; selective outcome reporting; and other sources of bias ${ }^{(17)}$. We used the Cochrane 'Risk of bias' tool in RevMan 5.1, which involved describing each of these domains as reported in the trial and then assigning a judgement about the adequacy of each entry as low, high or unclear risk of bias ${ }^{(18)}$. We presented this information in a 'Risk of bias' graph and summary.

\section{Statistical analysis}

Meta-analysis was performed in line with recommendations from the Cochrane collaboration and the quality of reporting of meta-analyses (QUORUM) guidelines ${ }^{(19,20)}$. From each study, dichotomous outcome data were summarised in $2 \times 2$ tables by two reviewers (VP, JP). The results were pooled and expressed as risk ratios (RR). Continuous variables were analyzed using mean differences (MD), with 95\% confidence intervals (Cls) ${ }^{(21)}$. The results were pooled using either a fixed effect ${ }^{(22)}$ or random effect model as appropriate ${ }^{(21)}$. For symptoms scores, the measurements used were sino-nasal outcome test score (SNOT 21) by Rotenberg et al. $(0-120){ }^{(23)}$ and Jorrisen et al. ${ }^{(12)}$. used their own score (0-50). Results for endoscopic scores were derived from four studies; Cote et al. ${ }^{(24)}$ and Rotenberg et al. ${ }^{(23)}$ used Lund-Kennedy endoscopic score (LKES score; range 0-12 in one nasal cavity) ${ }^{(25)}$; Chang et al. ${ }^{(26)}$ used Philpott-Javer score (range 0-40) (27) and Jorissen et al. ${ }^{(12)}$ used their own scoring system combining inflammation, oedema and polyps (range 0-6). We used standardised mean difference as a summary statistic in this meta-analysis because the included studies assessed the same outcome but measured it in a variety of ways, to standardise the results of the studies to a uniform scale before they could be combined.

Heterogeneity of the exposure effects was evaluated statistically using the $\mathrm{l}^{2}$ statistic to quantify heterogeneity across studies ${ }^{(28)}$. $A I^{2}$ value of $>50 \%$ was taken as evidence of substantial hetero-

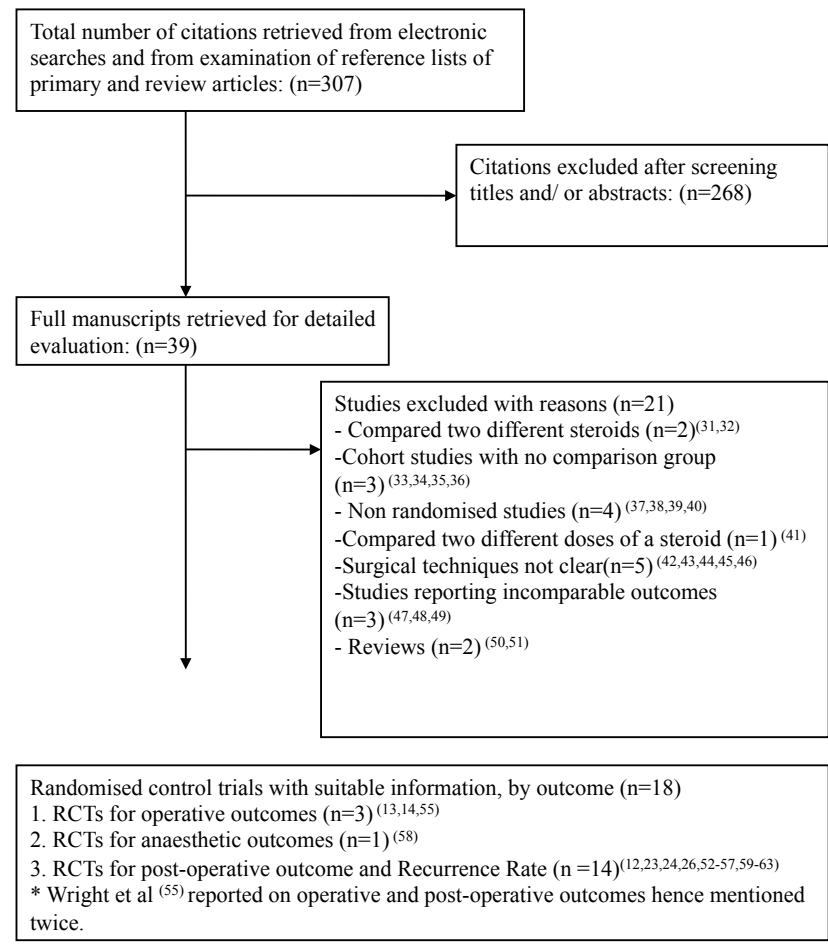

Figure 1. Consort diagram - Study selection process.

geneity and in such cases a random effect model was used. A chi-squared test for heterogeneity was also performed and the p-values are presented.

When only medians were available, these were used as estimates of means ${ }^{(29,30)}$. When a study failed to present a standard deviation (SD), this statistic was either calculated from the standard error of the mean, $95 \% \mathrm{Cl}, \mathrm{t}$ value or interquartile range ${ }^{(29)}$. Some studies provide only ranges, in such instances the SD was estimated using the formula total range/4 ${ }^{(30)}$. Statistical analyses were performed using RevMan 5 software.

\section{Results}

Study selection

Of the 307 citations identified by the search, 39 were selected after initial screening. Following examination of the full manuscripts of these 39 studies, 21 more were excluded; 2 studies compared different corticosteroids ${ }^{(31,32)}, 4$ studies were cohort studies with no comparison group ${ }^{(33-36)}, 4$ were non-randomised comparative studies ${ }^{(37-40)}, 1$ study compared two different doses of a steroid ${ }^{(41)}, 5$ studies did not use FESS as surgical technique (42-46), 3 studies reported incomparable outcomes ${ }^{(47-49)}$ and 2 were review articles ${ }^{(50,51)}$ (Figure 1).

Eighteen studies satisfied the selection criteria and were included in this review ${ }^{(12-14,23,24,26,52-63)}$. In total 1309 patients were included in this review. Four studies had an intrapatient control 


\begin{tabular}{|c|c|c|c|c|c|}
\hline & 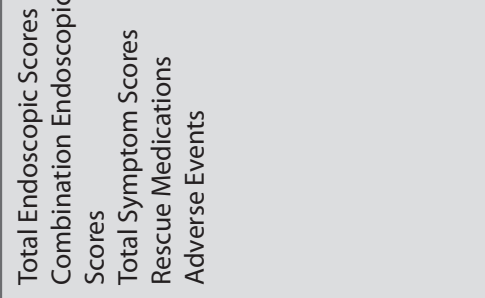 & 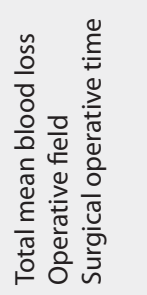 & 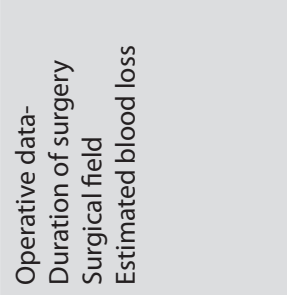 & 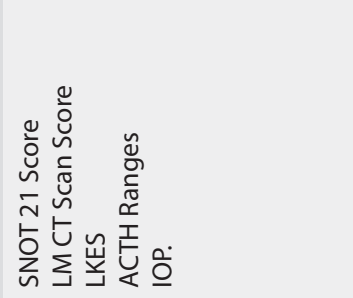 & 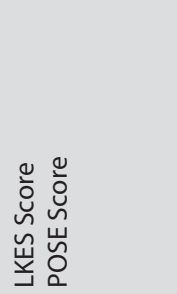 \\
\hline 흥 & ○ & ○ें & $\stackrel{\circ}{\circ}$ & ○ & $0^{\stackrel{\tilde{c}}{\stackrel{n}{ \pm}}}$ \\
\hline & 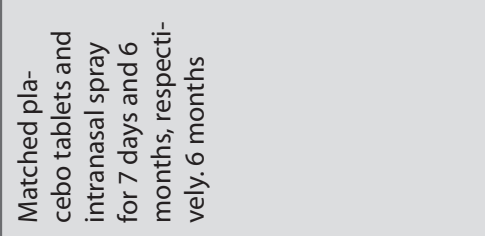 & 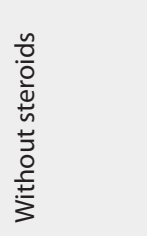 & 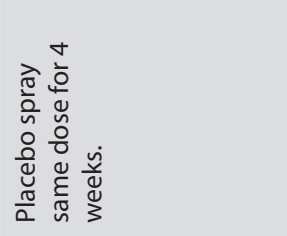 & 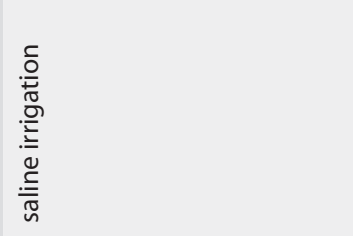 & 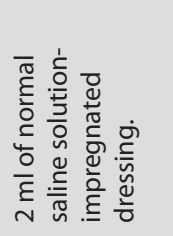 \\
\hline 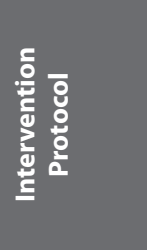 & 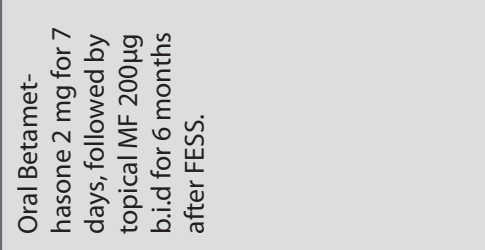 & 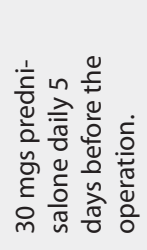 & 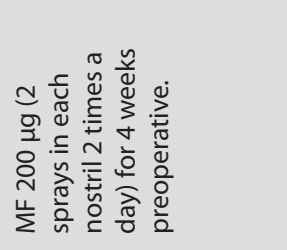 & 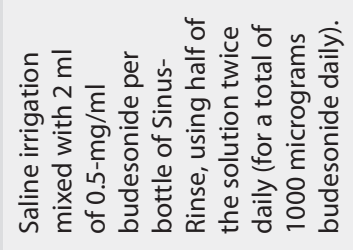 & 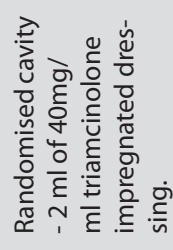 \\
\hline & 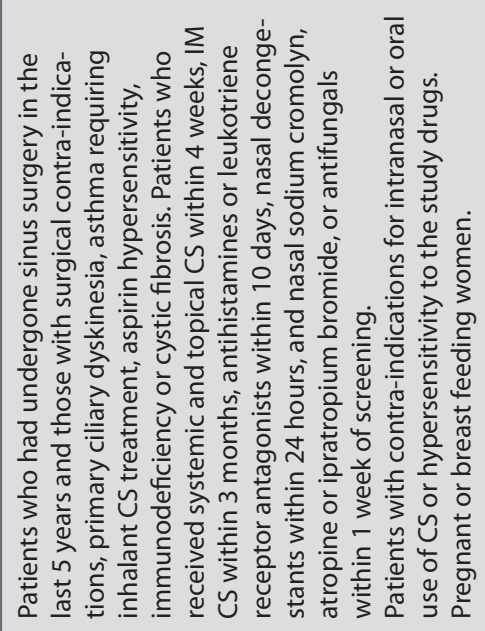 & 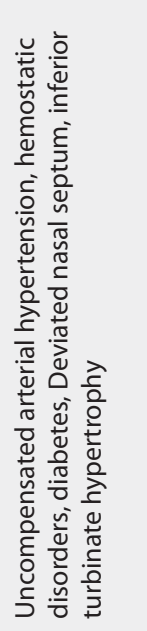 & 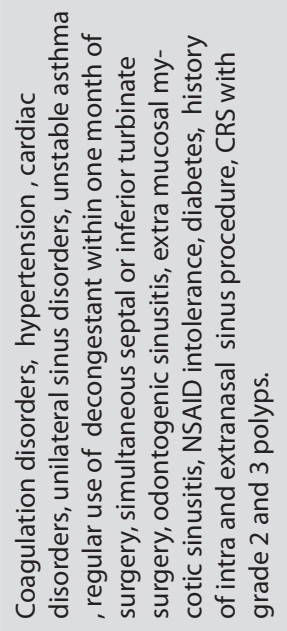 & 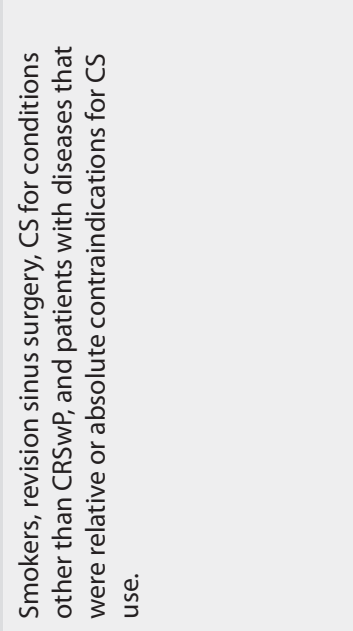 & 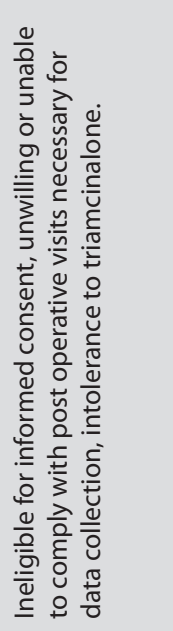 \\
\hline 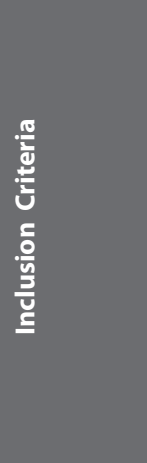 & 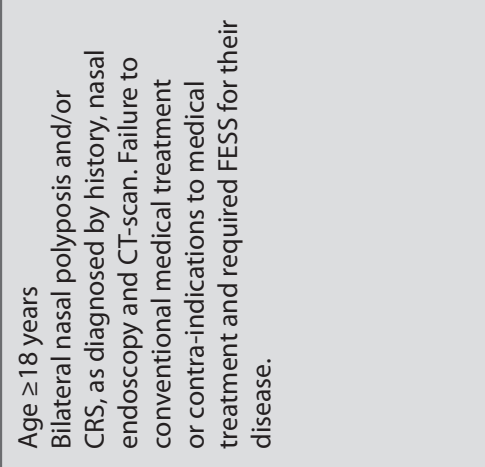 & 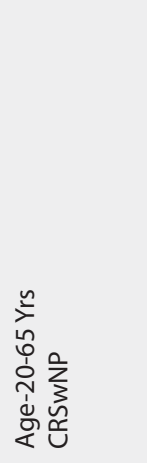 & 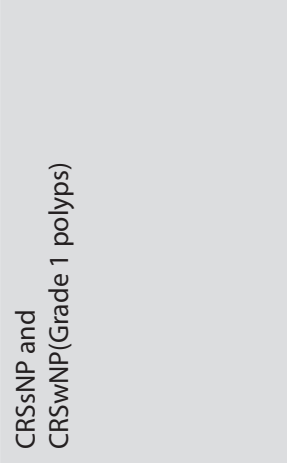 & 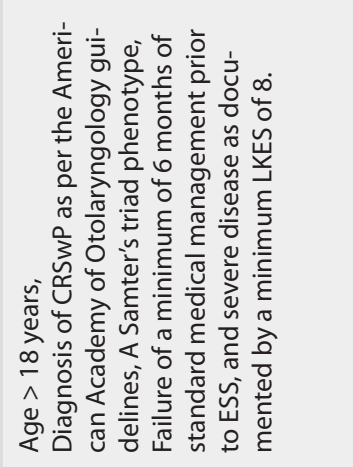 & 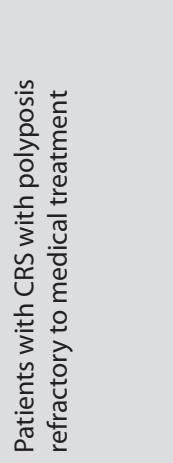 \\
\hline 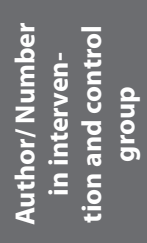 & 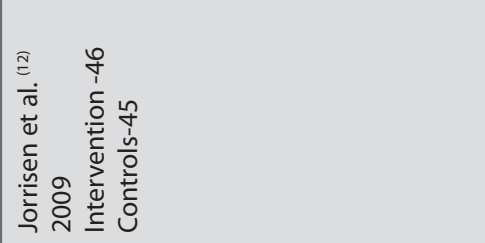 & 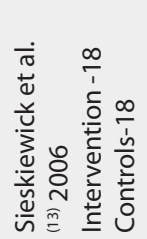 & 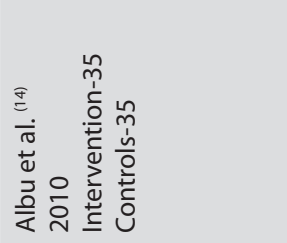 & 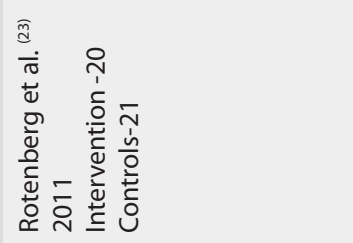 & 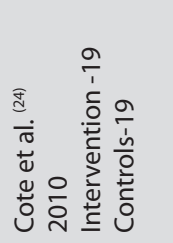 \\
\hline
\end{tabular}



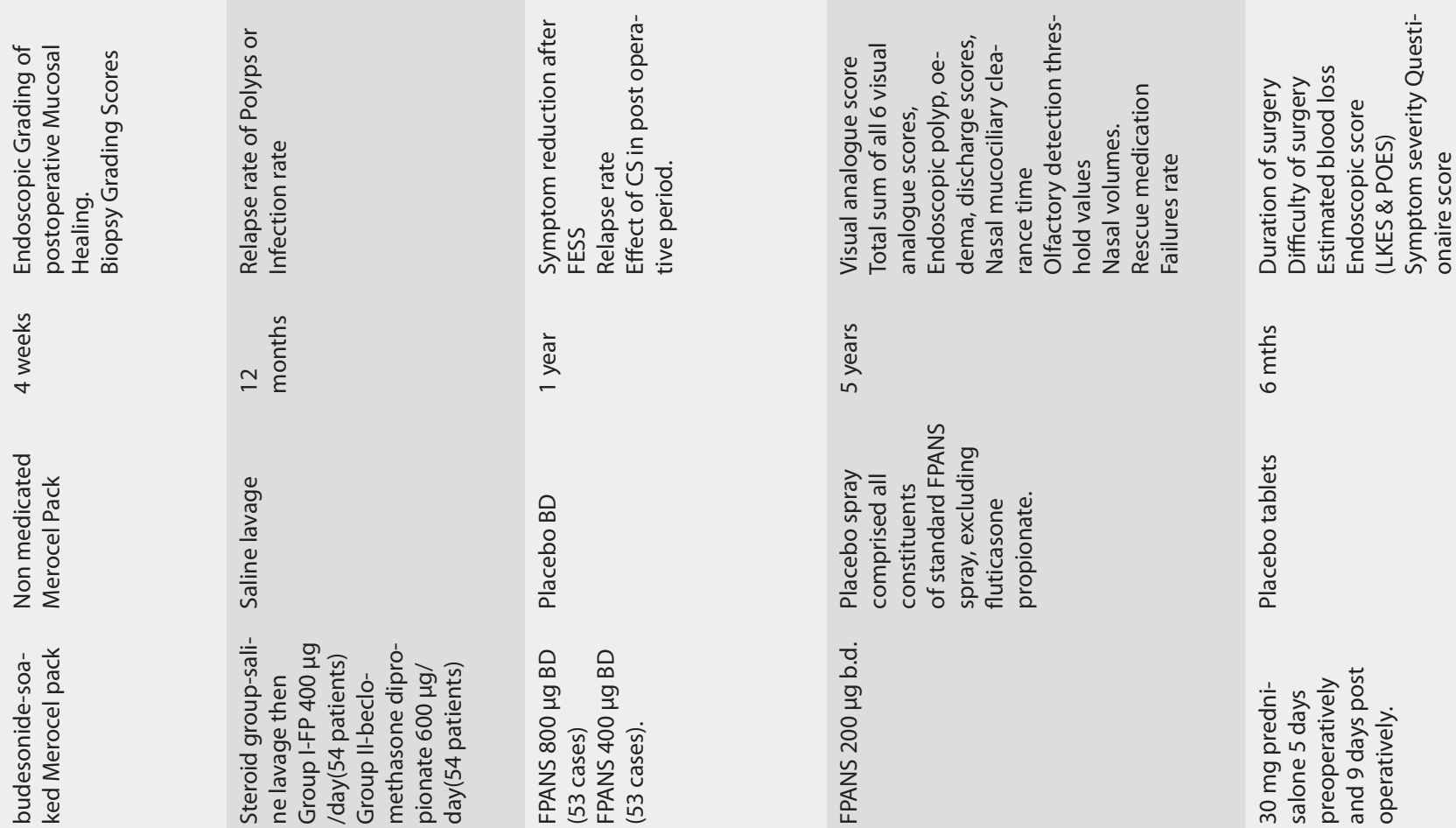

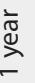

กั๊

$\frac{n}{\tilde{E}}$

00
0
$\frac{0}{0}$
$\frac{0}{0}$
$\frac{\pi}{0}$

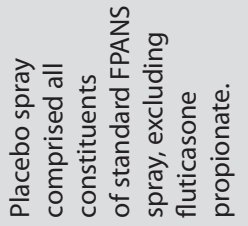

$\frac{\pi}{0}$
$\frac{0}{0}$
$\frac{0}{0}$
0
$\frac{0}{4}$
$\frac{\pi}{0}$
$\frac{\pi}{0}$

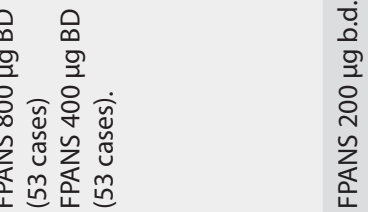

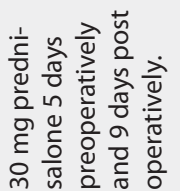

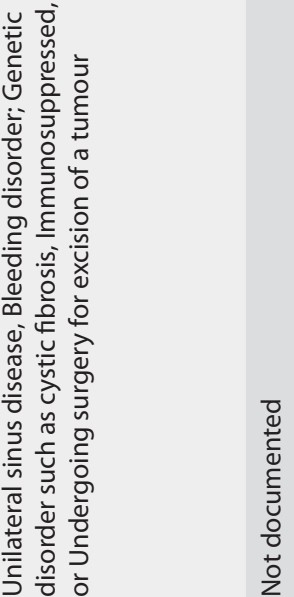
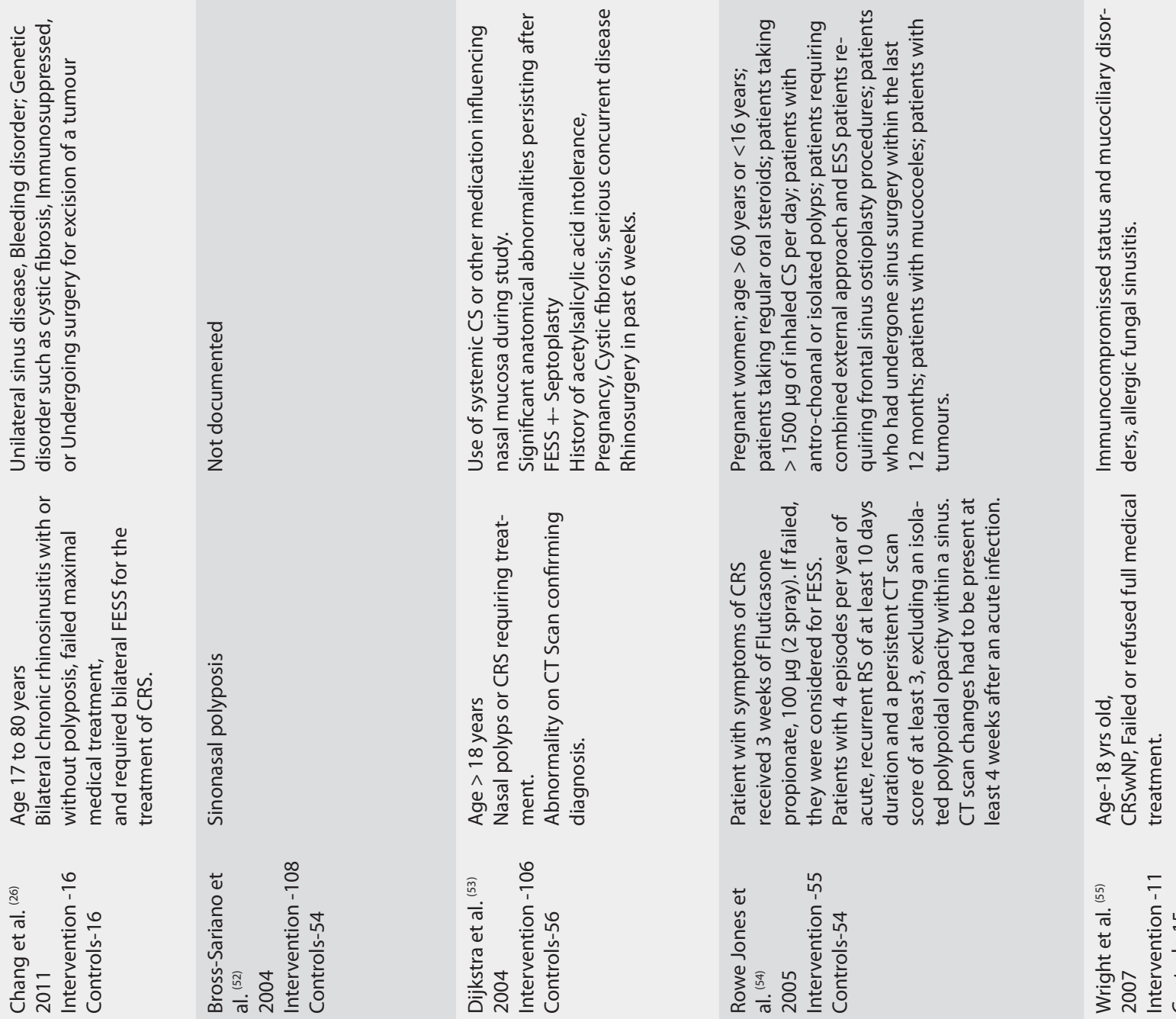

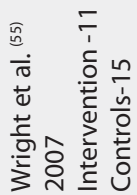




\begin{tabular}{|c|c|c|c|}
\hline 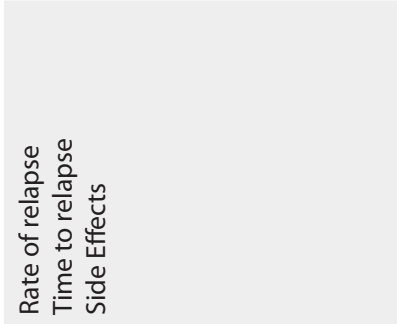 & 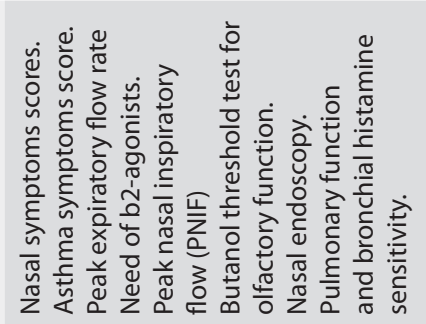 & 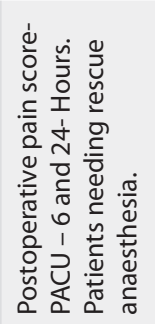 & 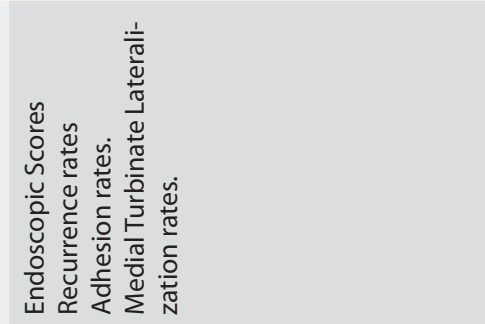 \\
\hline 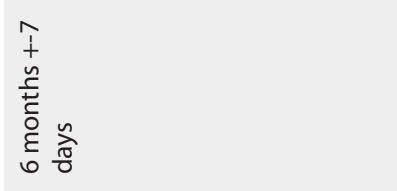 & 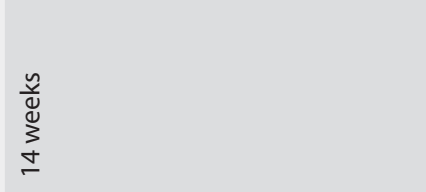 & 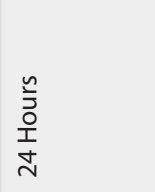 & 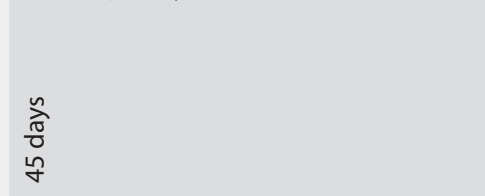 \\
\hline 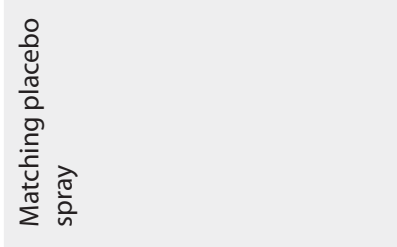 & 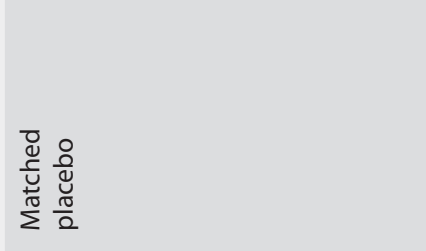 & 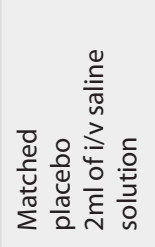 & 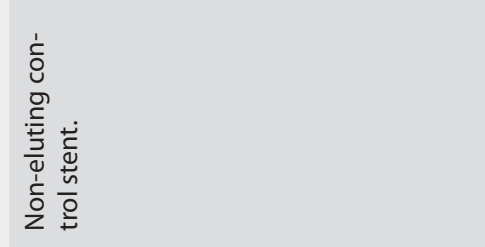 \\
\hline 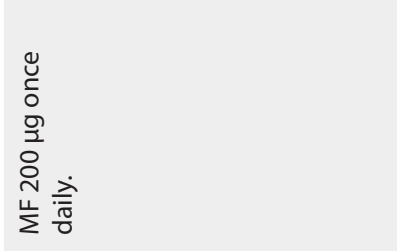 & 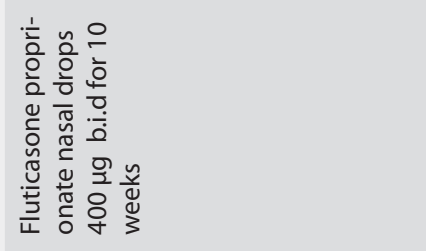 & 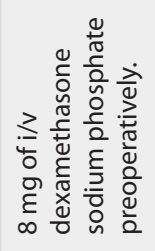 & 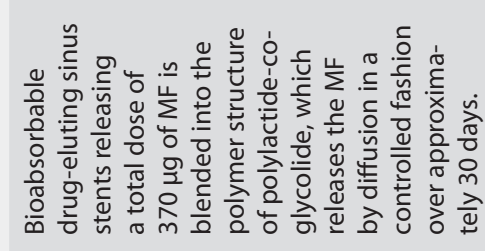 \\
\hline 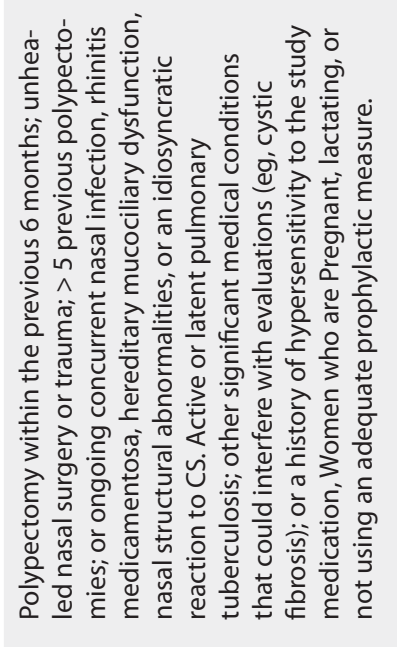 & 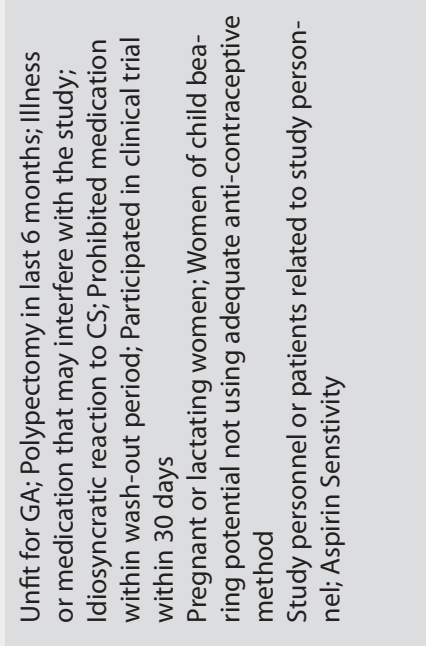 & 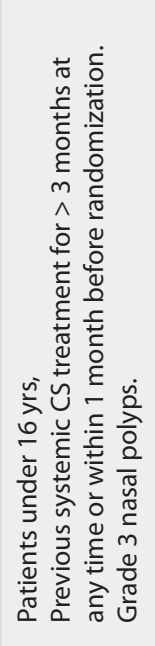 & 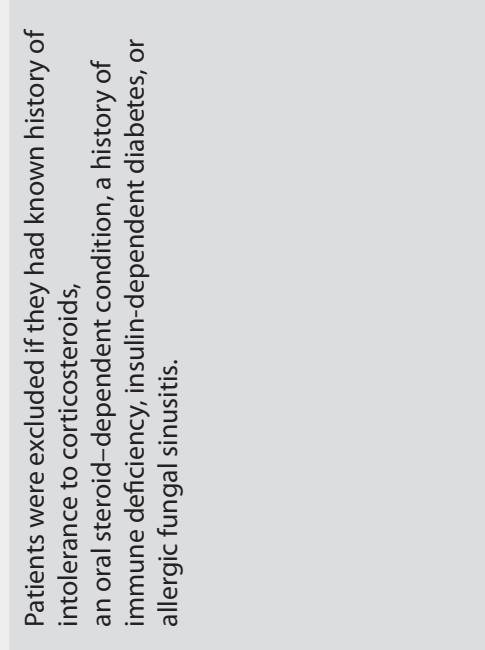 \\
\hline 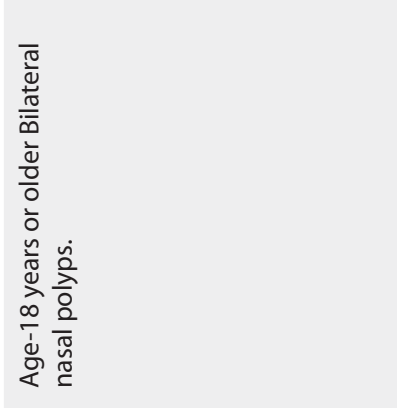 & 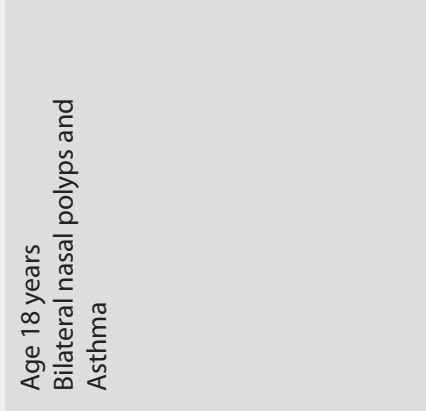 & 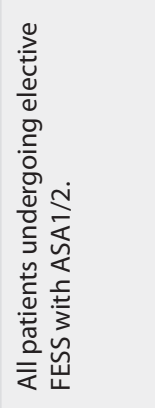 & 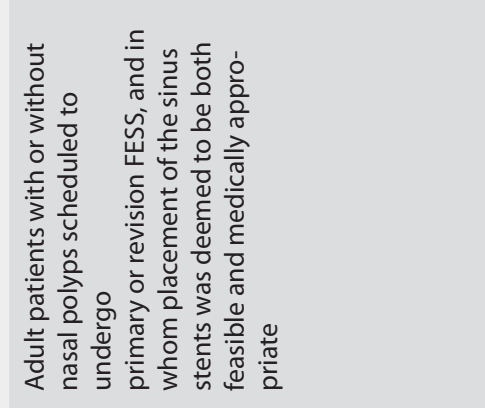 \\
\hline 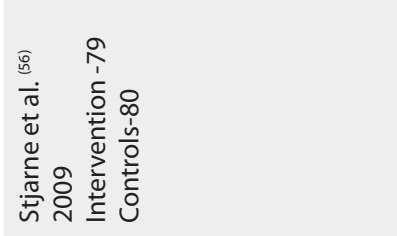 & 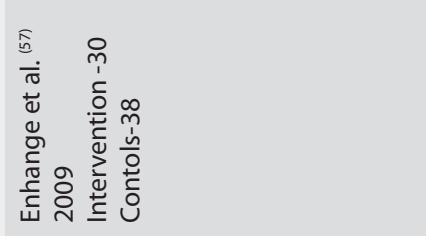 & 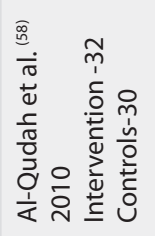 & 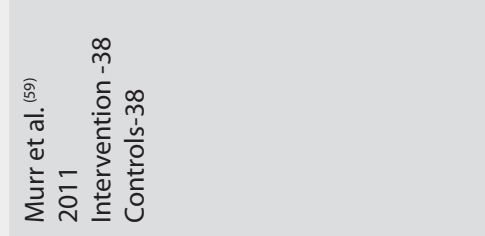 \\
\hline
\end{tabular}




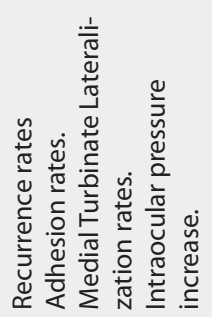

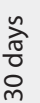

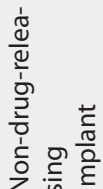

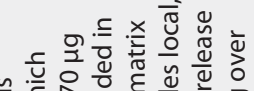

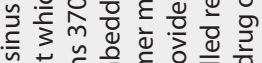

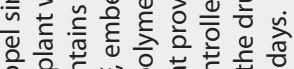

竞.

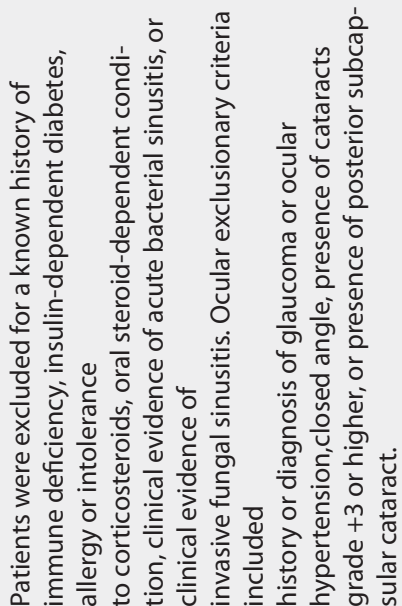

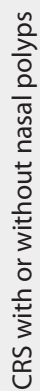

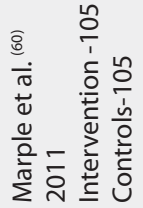

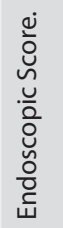

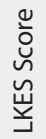

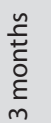
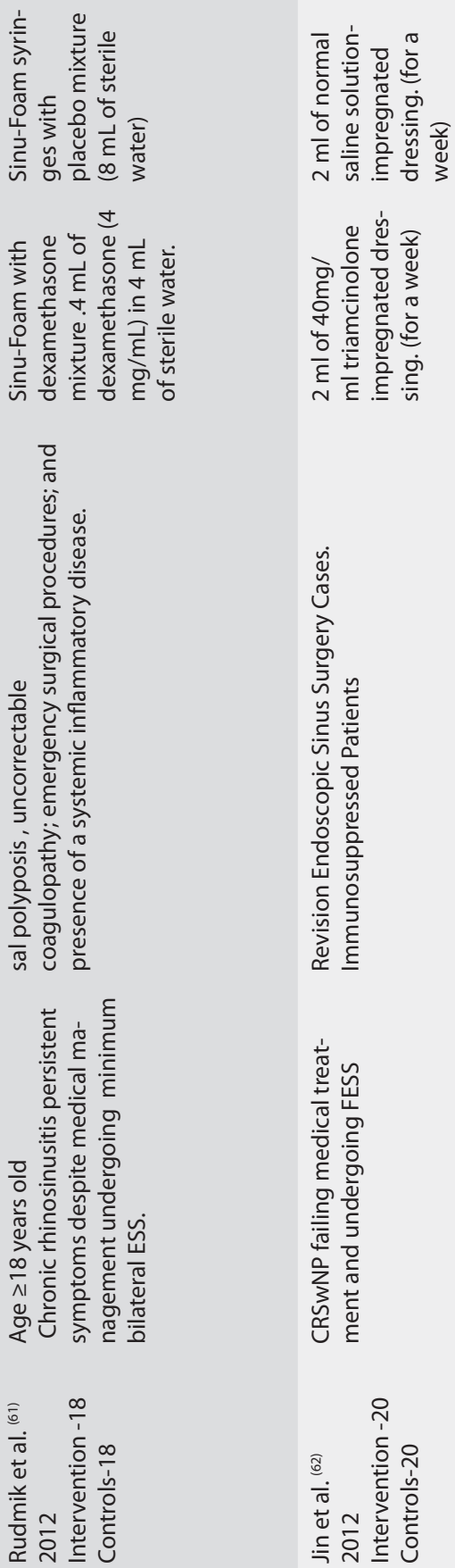

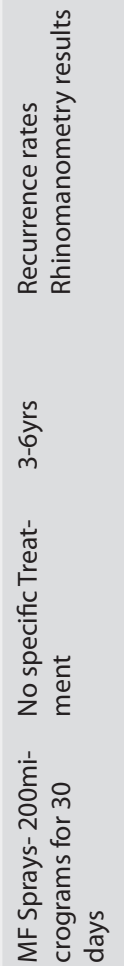

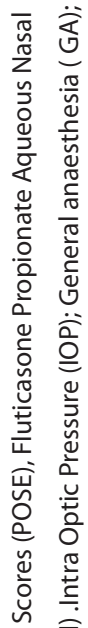

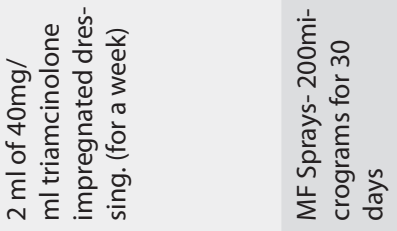

응 豆

을

:

$\stackrel{0}{2}$

竞

웜

岃

产

응

仓ั

ते त्๊

离

旁

곧

产

荣

䒕 党

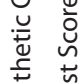

苞

这

苍造

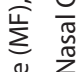

苋

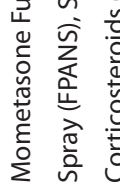




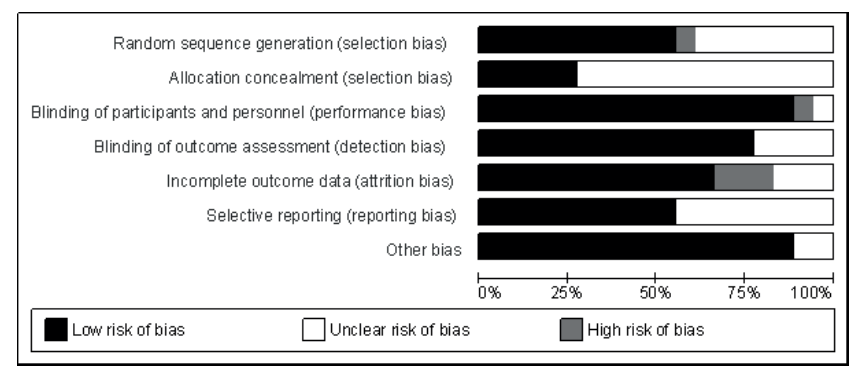

Figure 2. 'Risk of bias' graph: Each risk of bias item presented as percentages across all included studies.

design in which one side of the nasal cavity was compared with the other side $(n=182)^{(24,59,60,62)}$. These studies were included in the meta-analysis and the two groups treated as independent, and then sensitivity analysis was performed excluding these studies to determine the robustness of the results. The remaining 1127 patients were randomised to the steroid group of 607 patients and 520 controls. Sample size per study varied across the trials and ranged from 19 to 162 participants. Use of corticosteroids with FESS was reported for four categories; operative outcomes, anaesthesia related, post-operative outcomes and risk of recurrence. Operative outcomes were reported by three studies ${ }^{(13,14,5)}$; anaesthetic outcomes were reported by one study ${ }^{(58)}$; post-operative outcomes were reported by ten studies $(12,23,24,26,54,55,57,59,61,62)$, and risk of recurrence was reported by six studies $(52,53,56,59,60,63)$. One RCT reported both on operative and post-operative outcomes, therefore it was included in both categories ${ }^{(55)}$. Albu et al., reported on patients with and without polyps ${ }^{(14)}$; data from this study is included in the meta-analysis as Albu et al. ${ }^{(1)}$ and Albu et al. ${ }^{(2)}$. Albu et al. ${ }^{(1)}$ represent data of patients with CRSWNP and Albu et al. (2) represent data of patients with CRSsNP. In our attempt to get more information about studies with inadequate data, we received no response from the relevant authors $(13,24,53,55)$.

\section{Study characteristics}

A description of the included studies is summarised in Table 1. Risk of bias from the included studies is represented in Figures 2 and 3. Our judgements about each risk of bias item, presented as percentages across all included studies, are shown in Figure 2 , and for each risk of bias item for each included study in Figure 3. Generally, included studies had low risk of bias for method of randomisation and blinding, medium risk of bias for incomplete outcome data and selective reporting and unclear risk of bias for allocation concealment.

\section{Outcomes}

1. Operative outcomes in response to preoperative corticosteroids

\subsection{Operating time}

Data addressing this comparison were available from three

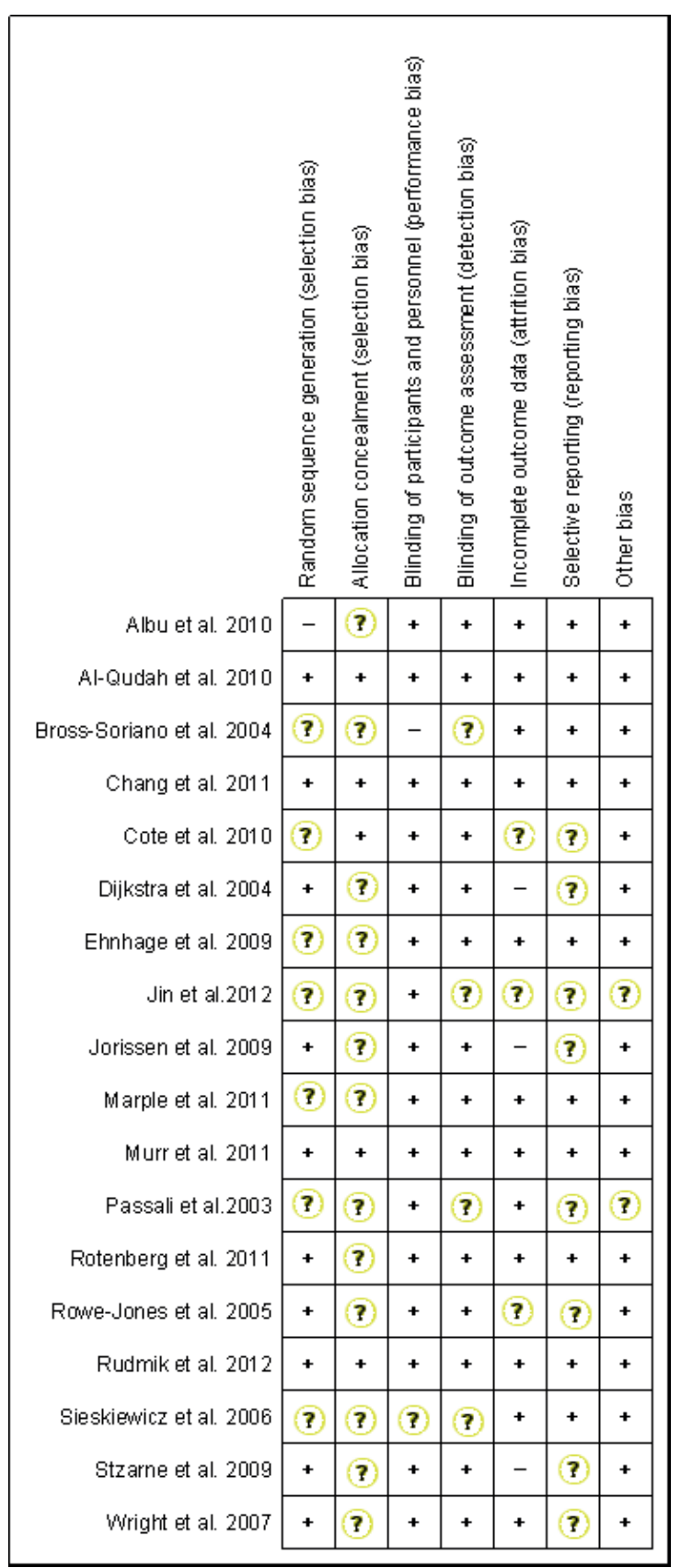

Figure 3. 'Risk of bias' summary: Each risk of bias item for each included study.

studies, Sieskiewicz et al. ${ }^{(13)}$, Albu et al. ${ }^{(14)}$ and Wright et al. ${ }^{(55)}$. Data from Wright et al. ${ }^{(55)}$ could not be included because the SD could not be calculated. Albu et al. ${ }^{(14)}$ used mometasone furoate nasal sprays for 4 weeks whereas Sieskiewicz et al. ${ }^{(13)}$ used $30 \mathrm{mgs}$ prednisalone for five days preoperatively. Pooling the results of the remaining two studies ${ }^{(13,14)}$ showed that, mean operative time was significantly lower in the steroid group compared to the non steroid group (MD -10.70 minutes; 95\% $\mathrm{Cl}-15.86,-5.55 ; \mathrm{P}<0.0001$; Figure $4 \mathrm{~A}$ ). $\mathrm{I}^{2}$ was $19 \%$, suggesting insufficient evidence of any significant heterogeneity $(X 2=2.47$, $\mathrm{P}=0.29$ ).

A subgroup analysis was done according to population group, 
A

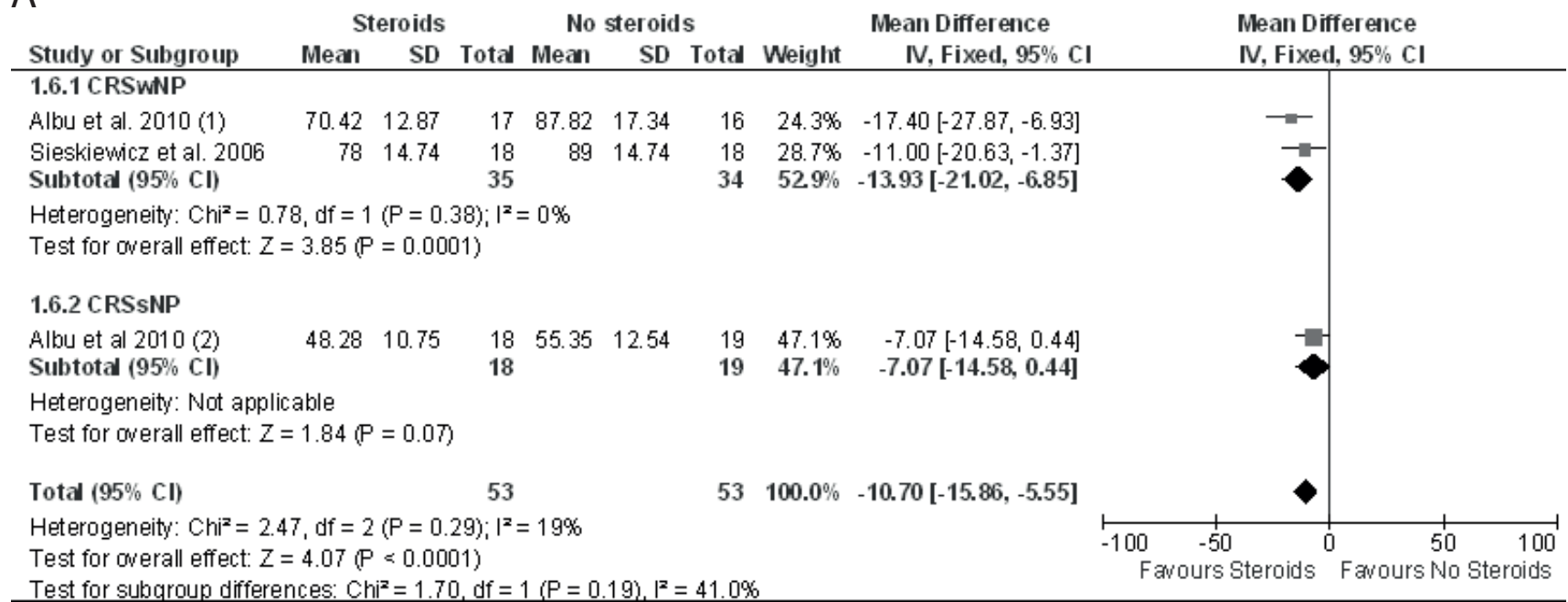

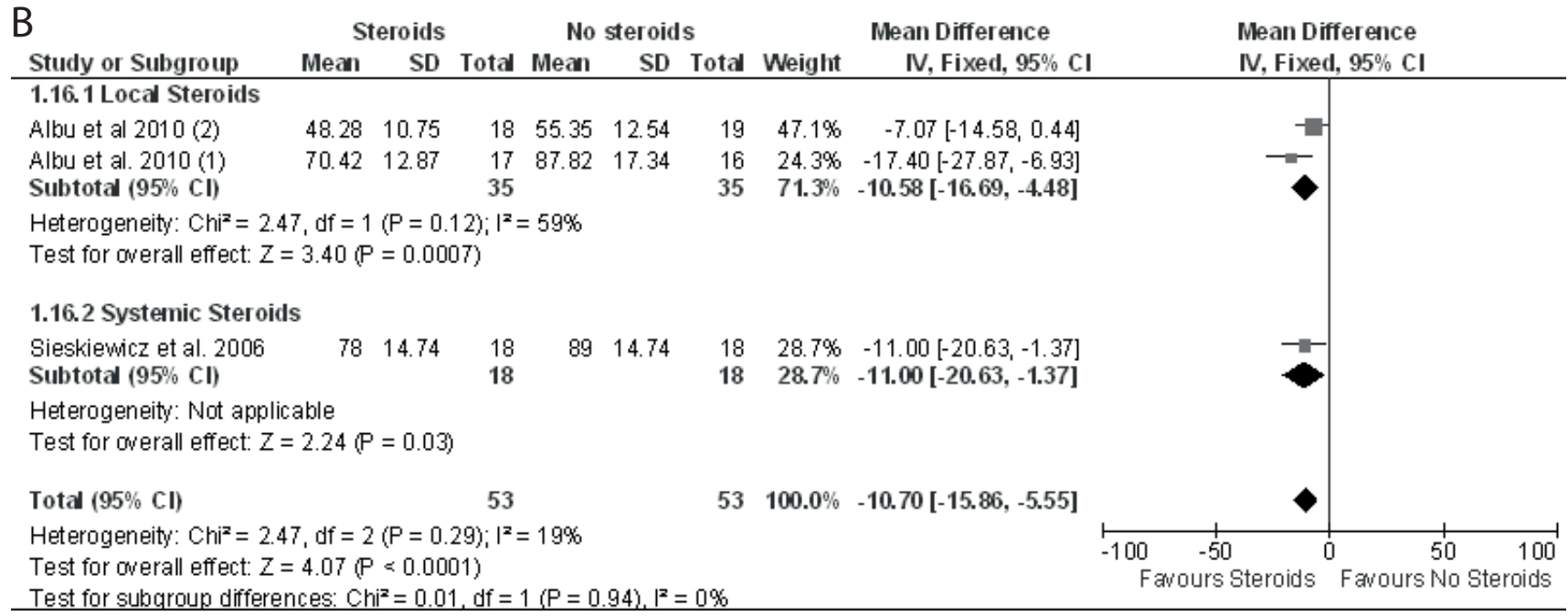

C

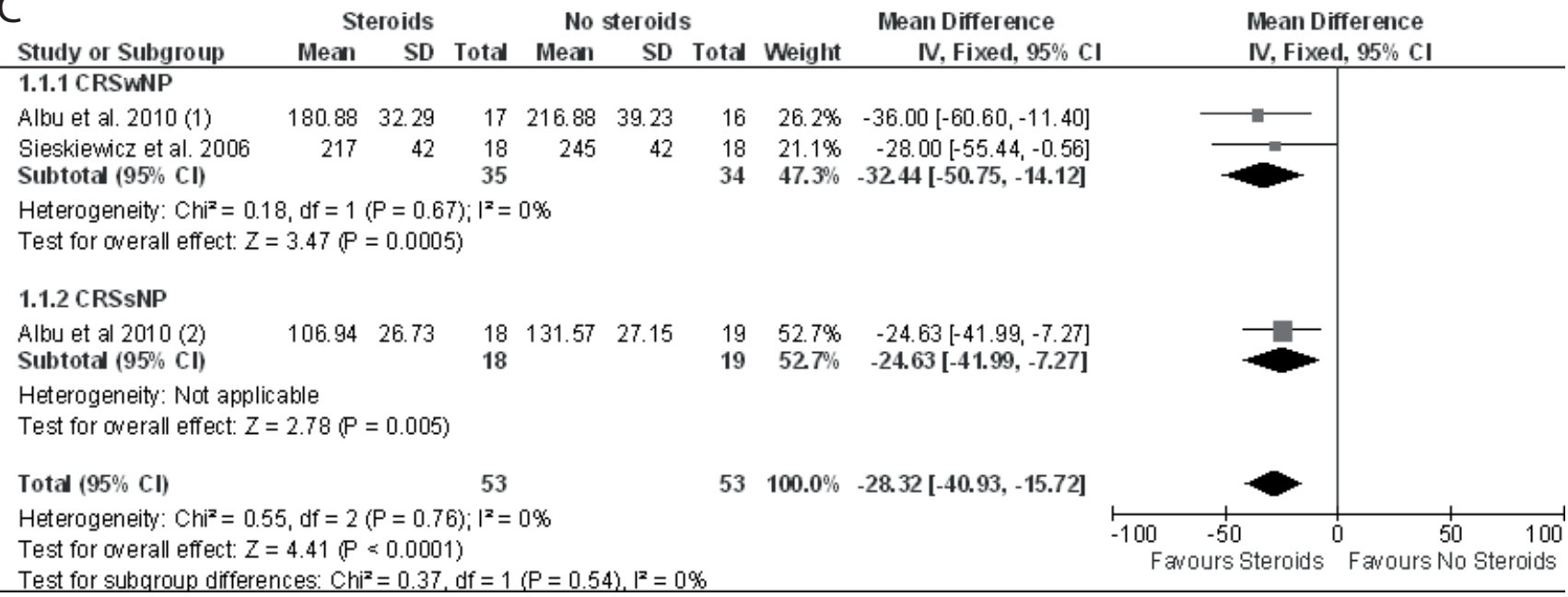

Figure 4. Forest plot of comparison - Operative outcomes. (A) Forest plot of comparison: Steroids versus No steroids. Outcome: 1.1 Operative time. Subgroup Analysis- Population Groups. (B) Forest plot of comparison: Steroids versus No steroids. Outcome: 1.1 Operative time. Subgroup AnalysisMode of Drug Delivery. (C) Forest plot of comparison: Steroids versus No steroids Outcome: 1.2 Estimated blood loss. Subgroup Analysis- Population Group 
D

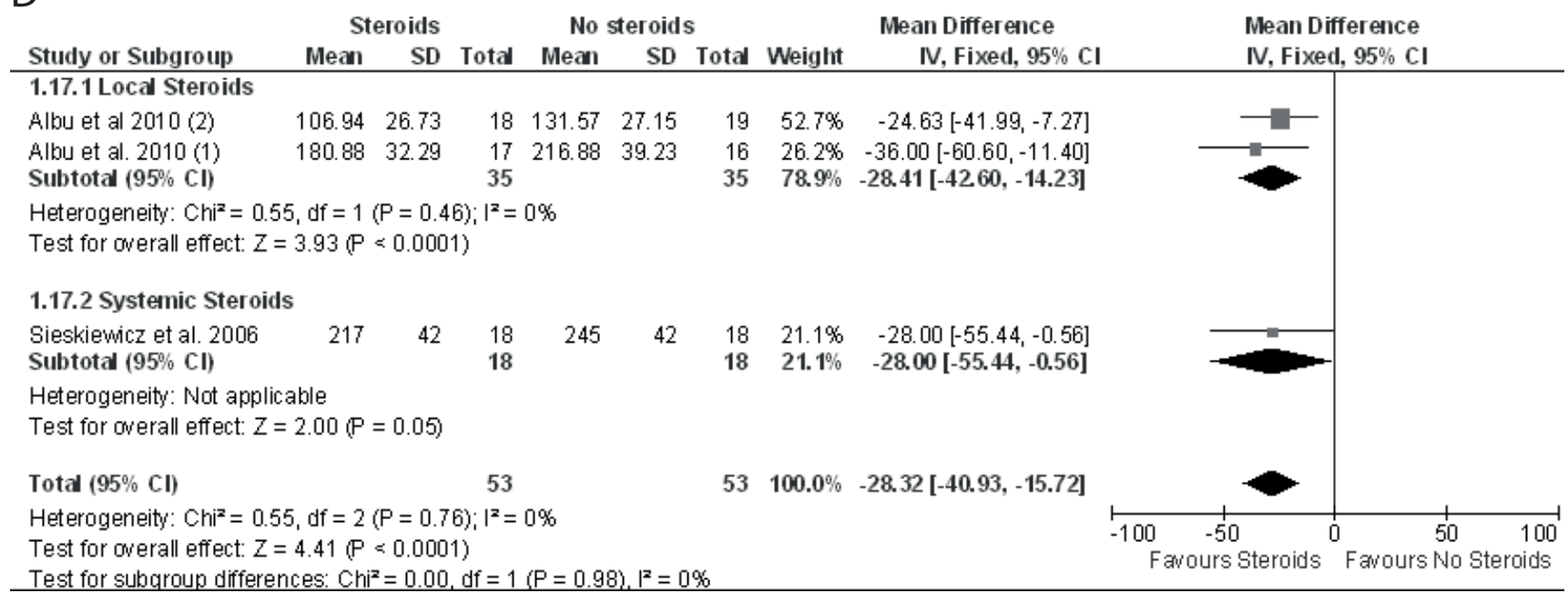

E

\begin{tabular}{|c|c|c|c|c|c|c|c|c|c|c|}
\hline \multirow{3}{*}{$\frac{\text { Study or Subgroup }}{\text { 1.5.1 CRSwNP }}$} & \multicolumn{3}{|c|}{ Steroids } & \multicolumn{3}{|c|}{ No steroids } & \multicolumn{2}{|c|}{ Mean Difference } & \multirow{2}{*}{\multicolumn{2}{|c|}{$\begin{array}{l}\text { Mean Difference } \\
\text { IV, Fixed, } 95 \% \mathrm{Cl}\end{array}$}} \\
\hline & \multirow[t]{2}{*}{ Mean } & SD & Total & \multirow[t]{2}{*}{ Mean } & \multirow[t]{2}{*}{ SD } & \multirow[t]{2}{*}{ Total } & \multirow[t]{2}{*}{ Weight } & \multirow[t]{2}{*}{ IV, Fixed, $95 \% \mathrm{Cl}$} & & \\
\hline & & & & & & & & & & \\
\hline Albu et al. 2010 (1) & 2.35 & 1.48 & 17 & 3.18 & 1.75 & 16 & $21.4 \%$ & $-0.83[-1.94,0.28]$ & & \\
\hline Sieskiewicz et al. 2006 & 2.4 & 1.14 & 18 & 3.3 & 1.14 & 18 & $47.4 \%$ & $-0.90[-1.64,-0.16]$ & & \\
\hline Subtotal $(95 \% \mathrm{Cl})$ & & & 35 & & & 34 & $68.8 \%$ & $-0.88[-1.50,-0.26]$ & & \\
\hline $\begin{array}{l}\text { Heterogeneity: } \mathrm{Chi}^{2}=0 . \\
\text { Test for overall effect: } Z\end{array}$ & $\begin{array}{l}1, \mathrm{df}=1 \\
2.78(\mathrm{P}\end{array}$ & $\begin{array}{l}(P=0 \\
=0.00\end{array}$ & 192): $1^{2}$ & & & & & & & \\
\hline 1.5.2 CRSsNP & & & & & & & & & & \\
\hline $\begin{array}{l}\text { Albu et al } 2010(2) \\
\text { Subtotal }(95 \% \text { Cl) }\end{array}$ & 2.06 & 1.37 & $\begin{array}{l}18 \\
18\end{array}$ & 2.72 & 1.48 & $\begin{array}{l}19 \\
19\end{array}$ & $\begin{array}{l}31.2 \% \\
31.2 \%\end{array}$ & $\begin{array}{l}-0.66[-1.58,0.26] \\
-\mathbf{0 . 6 6}[-\mathbf{1 . 5 8}, 0.26]\end{array}$ & & \\
\hline $\begin{array}{l}\text { Heterogeneity: Not applit } \\
\text { Test for overall effect: } Z\end{array}$ & $\begin{array}{l}\text { able } \\
=1.41(\mathrm{P}\end{array}$ & & & & & & & & & \\
\hline Total $(95 \% \mathrm{Cl})$ & & & 53 & & & 53 & $100.0 \%$ & $-0.81[-1.32,-0.30]$ & & \\
\hline $\begin{array}{l}\text { Heterogeneity: } \mathrm{Ch}^{2}=0.1 \\
\text { Test for overall effect: } Z\end{array}$ & $\begin{array}{l}6, d f=2 \\
=3.10(P\end{array}$ & $\begin{array}{l}2 \stackrel{P}{P}=0 . \\
=0.00 \\
z^{2}=0.1\end{array}$ & & & & & & & $\begin{array}{ll}-4 & -2 \\
\text { Favours Steroids }\end{array}$ & $\begin{array}{lll}0 & 2 & 4 \\
\text { Favours No Steroids }\end{array}$ \\
\hline
\end{tabular}

\begin{tabular}{|c|c|c|c|c|c|c|c|c|c|c|c|}
\hline \multirow{3}{*}{$\begin{array}{l}\text { F } \\
\text { Study or Subgroup } \\
1.18 .1 \text { Local Steroids }\end{array}$} & \multicolumn{3}{|c|}{ Steroids } & \multicolumn{3}{|c|}{ No steroids } & \multicolumn{3}{|c|}{ Mean Difference } & & \\
\hline & Mean & SD & Total & Mean & SD & Total & Weight & IV, Fixed, $95 \% \mathrm{CI}$ & & & \\
\hline & & & & & & & & & & & \\
\hline Albu et al 2010 (2) & 2.06 & 1.37 & 18 & 2.72 & 1.48 & 19 & $31.2 \%$ & $-0.66[-1.58,0.26]$ & & & - \\
\hline $\begin{array}{l}\text { Albu et al. } 2010(1) \\
\text { Subtotal }(95 \% \mathrm{CD}\end{array}$ & 2.35 & 1.48 & $\begin{array}{l}17 \\
35\end{array}$ & 3.18 & 1.75 & $\begin{array}{l}16 \\
35\end{array}$ & $\begin{array}{l}21.4 \% \\
52.6 \%\end{array}$ & $-0.83[-1.94,0.28]$ & & & \\
\hline \multicolumn{12}{|c|}{$\begin{array}{l}\text { Heterogeneity: } \mathrm{Chi}^{2}=0.05, \mathrm{df}=1(\mathrm{P}=0.82) ; \mathrm{I}^{2}=0 \% \\
\text { Test for overall effect: } Z=2.02(\mathrm{P}=0.04)\end{array}$} \\
\hline \multicolumn{12}{|c|}{ 1.18.2 Systemic Steroids } \\
\hline $\begin{array}{l}\text { Sieskiewicz et al. } 2006 \\
\text { Subtotal }(95 \% \mathrm{Cl})\end{array}$ & 2.4 & 1.14 & $\begin{array}{l}18 \\
18\end{array}$ & 3.3 & 1.14 & $\begin{array}{l}18 \\
18\end{array}$ & $\begin{array}{l}47.4 \% \\
47.4 \%\end{array}$ & $\begin{array}{l}-0.90[-1.64,-0.16] \\
-\mathbf{0 . 9 0}[-\mathbf{1 . 6 4},-\mathbf{0 . 1 6}]\end{array}$ & & & \\
\hline \multicolumn{12}{|c|}{$\begin{array}{l}\text { Heterogeneity: Not applicable } \\
\text { Test for overall effect: } Z=2.37(P=0.02)\end{array}$} \\
\hline Total $(95 \% \mathrm{Cl})$ & & & 53 & & & 53 & $100.0 \%$ & $-0.81[-1.32,-0.30]$ & & & \\
\hline $\begin{array}{l}\text { Heterogeneity: } \mathrm{Ch}^{2}=0 \\
\text { Test for overall effect: } z \\
\text { Test for subgroup differ }\end{array}$ & $\begin{array}{l}6, \mathrm{df}= \\
=3.10 \mathrm{f} \\
\text { aces: } \mathrm{Cl}\end{array}$ & $\begin{array}{l}P=0 \\
=0.0 \\
z=0 .\end{array}$ & $\begin{array}{l}0.92) ; 1^{2} \\
02) \\
\text { 11, } d f=\end{array}$ & & & & & & & $\begin{array}{c}-1 \\
\text { Favours Steroids }\end{array}$ & $\begin{array}{l}0 \\
0 \\
\text { Favours No Steroids }\end{array}$ \\
\hline
\end{tabular}

Figure 4. Forest plot of comparison - Operative outcomes. (D) Forest plot of comparison: Steroids versus No steroids. Outcome: 1.2 Estimated blood loss. Subgroup Analysis-Mode of Drug Delivery. (E) Forest plot of comparison: Steroids versus No steroids. Outcome: 1.3 -Surgical field quality. Subgroup Analysis- Population Groups. (F) Forest plot of comparison: Steroids versus No steroids. Outcome: 1.3 -Surgical field quality. Subgroup Analysis-Mode of Drug Delivery. 
which showed that in CRSwNP patients there was significant difference favouring steroid group (MD -13.93 minutes; 95\% $\mathrm{Cl}-21.02,-6.85 ; \mathrm{P}=0.0001$; Figure $4 \mathrm{~A}) . \mathrm{I}^{2}$ was $0 \%$, suggesting insufficient evidence of any significant heterogeneity $(X 2=0.78$, $P=0.38)$. CRSsNP did not show statistically significant difference between the two groups (MD -7.07 minutes; $95 \% \mathrm{Cl}-14.58$, $-0.44 ; \mathrm{P}=0.07$; Figure $4 \mathrm{~A})$.

As Albu et al. ${ }^{(14)}$ used local steroids and Sieskiewicz et al. ${ }^{(13)}$ used systemic steroids we undertook a subgroup analysis looking at different modes of delivery. This showed a significant difference in favour of corticosteroids both local (MD -10.58 minutes; $95 \%$ $\mathrm{Cl}-16.69,-4.48 ; \mathrm{P}=0.0007$; Figure $4 \mathrm{~B}$ ) and systemic (MD -11.00 minutes; $95 \% \mathrm{Cl}-20.63,-1.37 ; \mathrm{P}=0.03$; Figure 4B). In local corticosteroid subgroup analysis, $\mathrm{I}^{2}$ was $59 \%$, suggesting significant heterogeneity $\left(\mathrm{X}^{2}=2.47, \mathrm{P}=0.12\right)$.

\subsection{Estimated blood loss (EBL)}

Data addressing this comparison were available from three studies, Sieskiewicz et al. ${ }^{(13)}$, Albu et al. ${ }^{(14)}$ and Wright et al. ${ }^{\left({ }^{(5)} \text {. }\right.}$ Data from Wright et al. ${ }^{(55)}$ could not be included because the SD could not be calculated. Albu et al. ${ }^{(14)}$ used mometasone furoate nasal sprays for 4 weeks whereas Sieskiewicz et al. ${ }^{(13)}$ used 30 mgs prednisalone for five days preoperatively. Pooling of results from the remaining two studies ${ }^{(13,14)}$ showed that, mean EBL was significantly lower in the steroid group compared to the non steroid group (MD -28.32 mls; 95\% Cl -40.93, -15.72; P < 0.0001; Figure $4 \mathrm{C}) . \mathrm{I}^{2}$ was $0 \%$, suggesting no significant heterogeneity $(\mathrm{X} 2=0.55, \mathrm{P}=0.76)$.

A subgroup analysis was done according to population group, which showed significant difference favouring the steroid group in both CRSwNP patients (MD-32.44 mls; $95 \% \mathrm{Cl}-50.75,-14.12$; $\mathrm{P}=0.0005$; Figure $4 \mathrm{C}$ ) and CRSsNP patients (MD -24.63 mls; 95\% Cl -41.99, -7.27; P = 0.005; Figure 4C). In CRSwNP subgroup analysis, $I^{2}$ was $0 \%$, suggesting no significant heterogeneity $(\mathrm{X} 2=$ $0.18, \mathrm{P}=0.67)$.

As Albu et al. ${ }^{(14)}$ used local steroids and Sieskiewicz et al. ${ }^{(13)}$ used systemic steroids we undertook a subgroup analysis looking at different modes of delivery. This showed a significant difference in favour of corticosteroids both local (MD $-28.41 \mathrm{mls} ; 95 \% \mathrm{Cl}$ $-42.60,-14.23 ; \mathrm{P}<0.0001$; Figure 4D) and systemic (MD -28.00 minutes; $95 \% \mathrm{Cl}-55.44,-0.56 ; \mathrm{P}=0.05$; Figure 4D). In local corticosteroid subgroup analysis, $\mathrm{I}^{2}$ was $0 \%$, suggesting insignificant evidence of heterogeneity ( $x 2=0.55, P=0.46)$.

\subsection{Surgical field quality}

Data addressing this comparison were available from two studies, Sieskiewicz et al. ${ }^{(13)}$ and Albu et al. ${ }^{(14)}$. Both these studies used Boezaart grading system to measure surgical field quality. Albu et al. ${ }^{(14)}$ used mometasone furoate nasal sprays for 4 weeks whereas Sieskiewicz et al. ${ }^{(13)}$ used 30 mgs prednisalone for five days preoperatively. Pooling of the results of these showed that, surgical field quality was significantly better in the steroid group as compared to no steroid group (MD $-0.81 ; 95 \% \mathrm{Cl}-1.32$, $-0.30 ; \mathrm{P}=0.002$; Figure $4 \mathrm{E}) . \mathrm{I}^{2}$ was $0 \%$, suggesting no significant heterogeneity $(X 2=0.16, P=0.92)$.

A subgroup analysis was done according to population group, which showed significant difference favouring steroid group in CRSwNP patients (MD -0.88; 95\% Cl-1.50, -0.26; $\mathrm{P}=0.005$; Figure $4 \mathrm{E}$ ) but not in CRSsNP patients (MD $-0.66 ; 95 \% \mathrm{Cl}-1.58,0.26 ; \mathrm{P}=$ 0.16 ; Figure $4 \mathrm{~F}$ ). In CRSwNP subgroup analysis, $\mathrm{I}^{2}$ was $0 \%$, suggesting no significant heterogeneity $(X 2=0.01, P=0.92)$. As Albu et al. ${ }^{(14)}$ used local steroids and Sieskiewicz et al. ${ }^{(13)}$ used systemic steroids we undertook a subgroup analysis looking at different mode of delivery. This showed a significant difference in favour of corticosteroids both local (MD $-0.73 ; 95 \% \mathrm{Cl}-1.44$, $-0.02 ; \mathrm{P}=0.04$; Figure 4F) and systemic (MD -0.90; $95 \% \mathrm{Cl}-1.64$, $-0.16 ; \mathrm{P}=0.02$; Figure 4F). In local corticosteroid subgroup analysis, $I^{2}$ was $0 \%$, suggesting insignificant evidence of heterogeneity $(X 2=0.05, P=0.82)$.

2. Anaesthetic outcomes in response to intraoperative corticosteroids

This was reported by Al-Qudah ${ }^{(58)}$. They used $8 \mathrm{mg}$ dexamethasone intravenously in the steroid group. Analysis of data showed that there was no significant difference in post operative pain score at 6 hours postoperatively $(p=0.45)$ and 24 hours postoperatively $(p=0.17)$ in the steroid group as compared to the non steroid group.

\section{Postoperative outcomes in response to corticosteroids} Postoperative outcomes in the form of symptom score and endoscopic score were reported by twelve studies $(12,23,24,26,53-$ $57,59,61,62)$. Data from Rowe-Jones et al. could not be pooled in the meta-analysis as their data were not homogenous with other studies and SD could not be calculated ${ }^{(54)}$. Individual subjective symptom outcomes mainly, congestion, sense of smell and rhinorrhoea were reported in two studies Stjarne et al. and Enhange et al. but the data could not be pooled for meta-analysis $(56,57)$.

\subsection{Symptom score}

Even though postoperative symptom outcomes were reported by seven studies ${ }^{(12,23,53-57)}$ data from only two studies could be pooled for the meta-analysis. Jorrisen et al. ${ }^{(12)}$ used oral betamethasone $2 \mathrm{mg}$ for 7 days, followed by topical mometasone furoate $200 \mu \mathrm{g}$ twice daily and Rotenberg et al. ${ }^{(23)}$ used topical budesonide $1000 \mu \mathrm{g}$ daily. Data from Rowe-Jones et al. could not be pooled as their data was not homogenous with other studies ${ }^{(54)}$. They reported that overall visual analogue score, endoscopic polyp score and total nasal volume were significantly better in the steroid group at 5 years. Data from Dijkstra et al. and Wright et al. could not be included because the SD could 
A

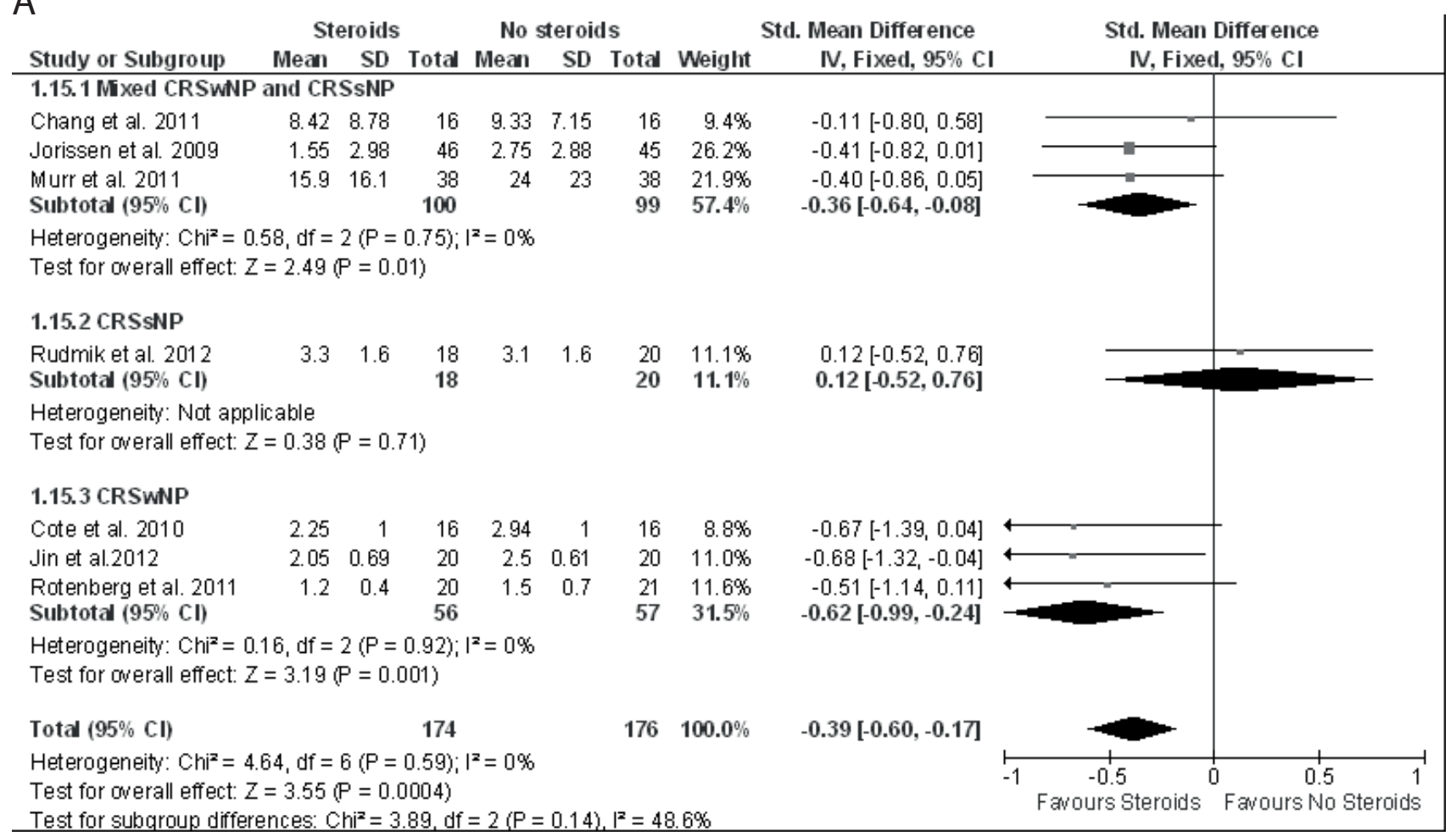

B

\begin{tabular}{|c|c|c|c|c|c|c|c|c|}
\hline \multirow{2}{*}{$\frac{\text { Study or Subgroup }}{\text { Bross-Soriano et al. } 2004}$} & \multicolumn{2}{|c|}{ Steroids } & No steroids & $\begin{array}{l}\text { oids } \\
\text { Total }\end{array}$ & \multicolumn{2}{|r|}{ Risk Ratio } & \multicolumn{2}{|c|}{$\begin{array}{c}\text { Risk Ratio } \\
\text { M-H, Fixed, } 95 \% \text { Cl }\end{array}$} \\
\hline & 1 & 108 & 2 & 54 & $15.4 \%$ & $0.25[0.02,2.70] 2004$ & & \\
\hline Rowe-Jones et al. 2005 & 7 & 55 & 9 & 54 & $52.5 \%$ & $0.76[0.31,1.90] 2005$ & & \\
\hline Jorissen et al. 2009 & 2 & 46 & 5 & 45 & $29.2 \%$ & $0.39[0.08,1.91] 2009$ & & \\
\hline Marple et al. 2011 & 1 & 104 & 0 & 104 & $2.9 \%$ & $3.00[0.12,72.80] 2011$ & & \\
\hline Total $(95 \% \mathrm{Cl})$ & & 313 & & 257 & $100.0 \%$ & $0.64[0.32,1.30]$ & & \\
\hline Total events & 11 & & 16 & & & & & \\
\hline $\begin{array}{l}\text { Heterogeneity: } \mathrm{Chi}^{2}=2.01 \\
\text { Test for overall effect: } Z=\end{array}$ & $\begin{array}{l}\text { If }=3(P= \\
24(P=0 .\end{array}$ & $\begin{array}{l}=0.57) ; \\
.22)\end{array}$ & $I^{2}=0 \%$ & & & & $\begin{array}{lc}1 & 1 \\
0.02 & 0.1 \\
\text { Favours Steroids }\end{array}$ & $\begin{array}{l}1 \\
1 \\
\text { Favours Control }\end{array}$ \\
\hline
\end{tabular}

Figure 5. Forest plot of comparison - Post-operative outcomes (A) Forest plot of comparison: Steroids versus No steroids. Outcome: 3.2 Post operative endoscopic score. (B) Forest plot of comparison: Steroids versus No steroids. Outcome: 3.4 Risk of infection (Sinusitis).

not be calculated ${ }^{(53,55)}$. Dijkstra et al. reported no significant difference in total symptom score between the steroid group and control group ${ }^{(53)}$. Individual subjective symptom outcomes mainly, congestion, sense of smell and rhinorrhoea, were reported by Stjarne et al., Enhange et al. and Wright et al., but could not be pooled for meta-analysis ${ }^{(55-57)}$. Wright et al. concluded that there was no treatment effect on subjective symptoms noted between corticosteroids compared with placebo ${ }^{(55)}$. Stjarne et al. reported no significant difference in baseline to end of treatment scores for nasal congestion and subjective sense of smell between the steroid and placebo group ${ }^{(56)}$. Similarly, Enhange et al. also reported that there were no statistically significant differences in the changes in all these nasal parameters between the steroid and the placebo group after undergoing FESS (57). Pooling of data from the remaining two studies ${ }^{(12,23)}$ showed that there was no significant difference in mean post operative symptom score between the steroid group compared to the non steroid group (SMD -0.01; $95 \% \mathrm{Cl}-0.36,0.33 ; \mathrm{P}=0.94$ ). $\mathrm{I}^{2}$ was $0 \%$, suggesting no significant heterogeneity $(X 2=0.36, P=0.55)$.

\subsection{Endoscopic score}

Data addressing this comparison were available from eight studies ${ }^{(12,23,24,26,55,59,61,62)}$. Jorrisen et al. ${ }^{(12)}$ used oral betamethasone 2 mg for 7 days, followed by topical mometasone furoate sprays, Rotenberg et al. ${ }^{(23)}$ used topical budesonide $1000 \mu \mathrm{g}$ daily, Cote et al. ${ }^{(24)}$ used triamcinolone impregnated packs, Chang et al. ${ }^{(26)}$ 


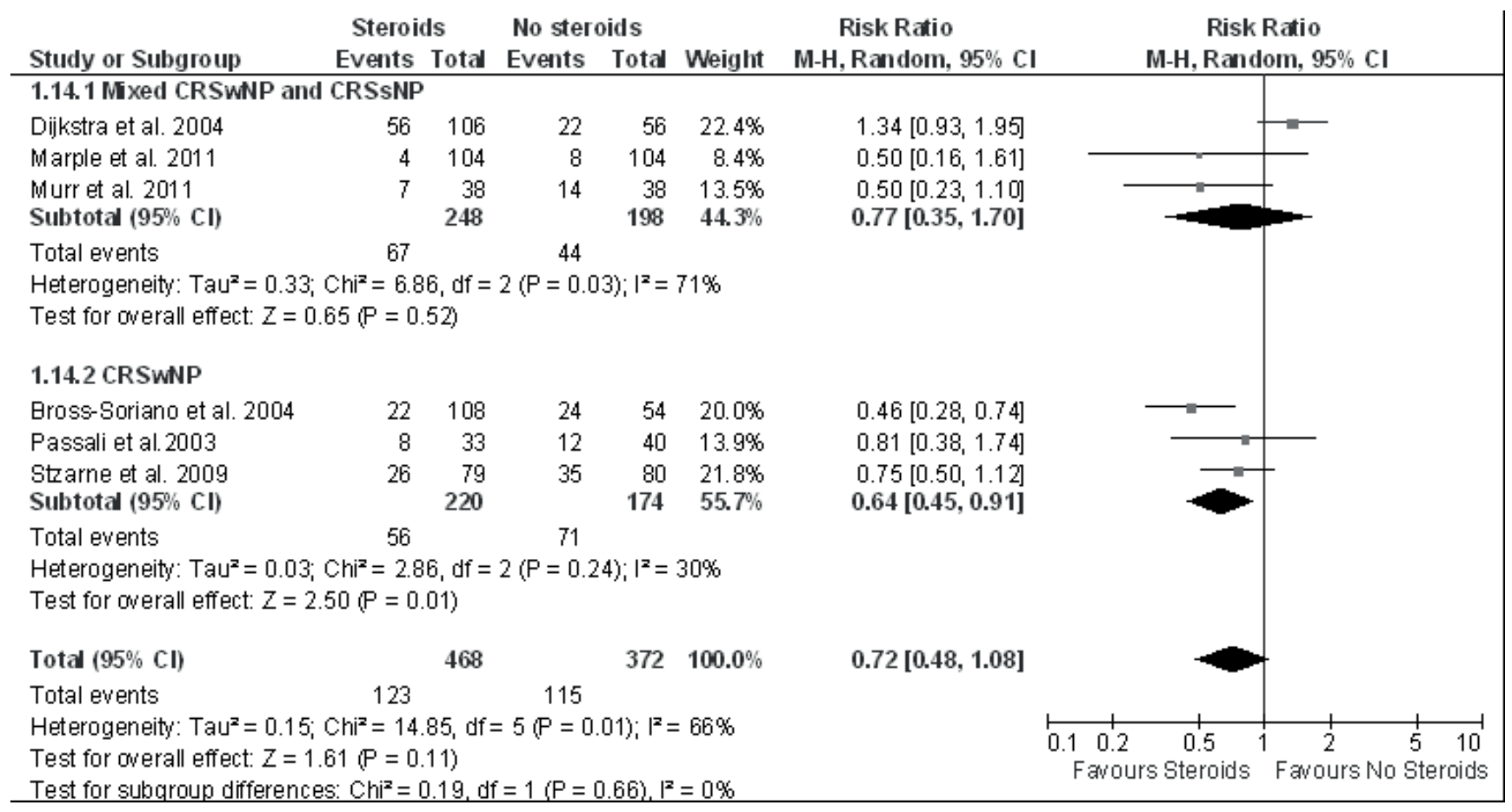

Figure 6. Forest plot of comparison-Recurrence Risk.

used budesonide impregnated packs, Murr et al. ${ }^{(59)}$ and Rudmik et al. ${ }^{(61)}$ used mometasone furoate eluding stents, and Jin et al. ${ }^{(62)}$ used sinufoam with dexamethasone dressing. Data from Wright et al. could not be included because the SD could not be calculated ${ }^{(55)}$. Pooling of data from the remaining seven studies $(12,23,24,26,59,61,62)$ showed that there was significant difference in mean post operative endoscopic scores between the steroid group as compared to no steroid group (MD -0.39; $95 \% \mathrm{Cl}-0.60$, $-0.17 ; P=0.0004$; Figure $5 \mathrm{~A}$ ). $\mathrm{I}^{2}$ was $0 \%$, suggesting no significant heterogeneity ( $\mathrm{X} 2=4.64, \mathrm{P}=0.59)$.

A subgroup analysis was performed to assess the results according to the population group. Three studies reported data from mixed population, CRSwNP and CRSsNP ${ }^{(12,26,59)}$, one study reported data from CRSsNP patients ${ }^{(61)}$ whereas three other studies showed data from CRSWNP ${ }^{(23,24,62)}$. No significant difference between steroid and no corticosteroids were found in the CRSsNP group (SMD 0.12; 95\% Cl - 0.52, 0.76; Figure 5A).Analysis of studies reporting on CRSwNP showed significant difference between steroid and no steroid groups (SMD -0.62; $95 \% \mathrm{Cl}-0.99$, $-0.24 ; \mathrm{P}=0.001 ;$ Figure $5 \mathrm{~A}$ ). $\mathrm{I}^{2}$ was $0 \%$, suggesting no significant heterogeneity, $(X 2=0.16, P=0.92)$. Analysis of data from the mixed population group also showed significant difference between the steroid and no steroid groups (SMD $-0.36 ; 95 \% \mathrm{Cl}$ $-0.64,-0.08 ; P=0.01$; Figure $5 A) . I^{2}$ was $0 \%$, suggesting no significant heterogeneity, $\left(\mathrm{X}^{2}=0.58, \mathrm{P}=0.75\right)$

\subsection{Risk of sinusitis}

Risk of sinusitis as an adverse event associated with the use of corticosteroids was reported by four studies ${ }^{(12,52,54,60)}$. Cote et al. ${ }^{(24)}$ used triamcinolone impregnated packs, Bross-Sariano et al. ${ }^{(52)}$ used fluticasone or beclomethasone spray, Rowe-Jones et al. ${ }^{(54)}$ used fluticasone sprays, and Marple et al. ${ }^{(60)}$ used mometasone furoate releasing stents. Pooling of the results showed no significant difference between use of corticosteroids and no corticosteroids (RR 0.64; 95\% Cl 0.32, 1.30; $\mathrm{P}=0.22$; Figure 5B). $\mathrm{I}^{2}$ was $0 \%$, suggesting no significant heterogeneity $(\mathrm{X}=2.01, \mathrm{P}=$ $0.57)$.

\section{Recurrence risk}

Risk of recurrence was reported by six studies ${ }^{(52,53,56,59,60,63)}$. BrossSariano et al. ${ }^{\left({ }^{(2)}\right)}$ used fluticasone or beclomethasone spray, Dijkstra et al. ${ }^{(53)}$ used fluticasone nasal sprays, Stjarne et al. ${ }^{(56)}$ and Passali et al. ${ }^{(63)}$ used mometasone furoate nasal sprays whereas Murr et al. ${ }^{(59)}$ and Marple et al. ${ }^{(60)}$ used mometasone furoate eluding stents. Pooling of results of these studies showed no significant difference between use of corticosteroids and no corticosteroids (RR 0.72; $95 \% \mathrm{Cl} 0.48,1.08 ; \mathrm{P}=0.11$; Figure 6 ). $\mathrm{I}^{2}$ was $66 \%$, suggesting significant heterogeneity $(X 2=14.85, P=0.01)$. A subgroup analysis was performed to assess the results according to the population group. Three studies reported data from mixed population, CRSwNP and CRSsNP ${ }^{(54,60,61)}$ whereas three other studies showed data from CRSwNP $(53,57,64)$. No significant difference between steroid and no corticosteroids were found in the mixed population group (RR $0.77 ; 95 \% \mathrm{Cl} 0.35,1.70 ; \mathrm{P}=0.52$; Figure 6$). I^{2}$ was $71 \%$, suggesting significant heterogeneity, ( $\mathrm{X} 2=$ $6.86, P=0.03)$. Analysis of studies reporting on CRSwNP showed 
significant difference between steroid and no steroid groups (RR $0.64 ; 95 \% \mathrm{Cl} 0.45,0.91 ; \mathrm{P}=0.01$; Figure 6$). \mathrm{I}^{2}$ was $30 \%$, suggesting no significant heterogeneity, $\left(X^{2}=2.86, P=0.24\right)$.

\section{Discussion}

\section{Principal findings of the review}

This systematic review and meta-analysis of randomised controlled trials for operative outcomes demonstrated that operative time and estimated blood loss were significantly lower, and surgical field quality was significantly better in the local and/ or systemic steroid group compared to the non steroid group. These results were based on two studies, Albu et al. ${ }^{(14)}$ used local steroids and Sieskiewicz et al. ${ }^{(13)}$ used systemic steroids. In relation to anaesthetic outcomes in response to intra-operative corticosteroids there was no significant difference in post operative pain scores between the two groups. For post-operative outcomes in response to the corticosteroids there was no significant difference in symptom scores but endoscopic scores were better for the steroid group between the two groups. The use of corticosteroids was not associated with an increased risk of sinusitis. There was no significant difference in the recurrence risk between those given corticosteroids and controls in mixed population group, but subgroup analysis showed favourable results for steroid use in cases of CRSwNP.

\section{Strengths of the review}

CRS is an inflammatory disease and therefore, corticosteroids have long been utilized in its management due to their potent anti-inflammatory properties. Patients who fail to respond to medical therapy are considered for FESS. FESS differs from traditional, radical and less physiological drainage procedures as it restores mucociliary clearance pathways and ventilation by opening the osteomeatal complex and is customized to disease extent. Corticosteroids have been indicated in FESS for various reasons. Our review included studies reporting use of corticosteroids on the operative outcome, anaesthetic related outcome, postoperative outcome and recurrence risk when used with FESS.

An important factor affecting the success of FESS is a clean surgical field ${ }^{(64)}$. Poor endoscopic view secondary to bleeding is associated with increased operative time, complications and even cessation of surgery ${ }^{(64,65)}$. Preoperative corticosteroid treatment has been proposed to minimise bleeding and improve surgical field ${ }^{(66,67)}$. Corticosteroid reduce intra operative bleeding by not just their anti-inflammatory effect but also have a positive effect on regulation of vascular tone. Various mechanisms explaining this positive effect of corticosteroids on the vascular tone have been proposed ${ }^{(68)}$. These include potentiation of action of other $a$ adrenergic agonists like norepinephrine at the receptor level. Our meta-analysis for operative outcomes including operative time, EBL and surgical field quality showed significant benefit from the use of preoperative corticosteroids, both systemic ${ }^{(13)}$ and topical ${ }^{(14)}$. Even though these studies varied in definitions of CRS (CRSsNP and CRSwNP), timing and commencement of corticosteroids, and type, volume and route of administration of corticosteroids, the benefit was seen consistently in all three studies. Though we could not include the data from Wright et al. in our meta-analysis, these authors also concluded that patients who were not given pre-operative corticosteroids showed a higher percentage of severely inflamed mucosa and were associated with technically more difficult surgery ${ }^{(55)}$.

Patients after FESS may experience pain which might prevent them from returning to normal daily activities ${ }^{(69)}$. Corticosteroids due to their potent anti-inflammatory effect have been proposed in the management of acute surgical and postoperative pain control ${ }^{(16)}$. In this respect one study was found to assess the outcome of intra-operative corticosteroid in reducing pain after FESS ${ }^{(58)}$. This study did not show any benefit of using intraoperative steroid as a tool to reduce post operative pain.

\section{Comparison with other studies}

Due to the anti-inflammatory effects and excellent safety profile, topical nasal corticosteroids have become a common treatment modality for $C R S{ }^{(70)}$. A previous systematic review on use of topical corticosteroids following FESS reporting a significant improvement in symptoms, endoscopic appearance and delay in polyp recurrence, recommended the use of nasal corticosteroids after FESS ${ }^{(70)}$. However, these authors did not perform a meta-analysis and summarized their recommendations based on individual studies. Subgroup analysis from a Cochrane review (71) on use of corticosteroids in CRS based on two studies showed benefit of steroid on symptom scores who had sinus surgery ${ }^{(12,36)}$. However, the study by Lavigne et al. had to be excluded from our study as it recruited patients with failed FESS, and therefore does not fulfil the inclusion criteria.

Recent EPOS 2012 systematic review on the role of corticosteroids in postoperative treatment for adults with CRS recommended, topical corticosteroids for patients with CRSsNP; and both topical and oral corticosteroids in patients with CRSwNP ${ }^{(4)}$. This document, in a subgroup analysis showed that only patients with prior surgery for CRSsNP had symptom improvement but there was no improvement for those patients without surgery. Similarly, in CRSwNP, patients with sinus surgery responded to topical steroid greater than patients without sinus surgery in polyp size reduction but improvement in symptoms and nasal airflow was not statistically different between the two subgroups. The meta-analysis in the EPOS 2012 document incorporates studies which include patients who have had a history of sinus surgery including polypectomy. Whereas in our meta-analysis 
all patients underwent FESS. Our meta-analysis showed no significant benefit with the use of corticosteroids in post-operative symptom outcomes.

It has been postulated that, use of corticosteroids in the immediate post operative period may increase the risk of sinusitis ${ }^{(32)}$. Our meta analysis from four studies which used local corticosteroids, showed that there was no evidence of increased risk of sinusitis with steroid use in postoperative period. We acknowledge that rare adverse events are possibly not detected in RCTs. However, they were extremely low and there was no difference in adverse events between the study groups and control groups in any trial.

\section{Limitations of the review}

Limitations of our systematic review include potential biases in the review process regarding the eligibility criteria and data analyses. The inclusion of trials studying mixed populations of polyps and non-polyps patients possibly brings heterogeneity. We decided to include trials with mixed populations in patients with CRS with or without polyps, since this is inline with the definition of CRS by the European Position Paper $2012^{(4)}$. We also included four trial which used a paired intrapatient design, but treating the two groups as independent. Sensitivity analysis omitting these trials showed that the pooled results remained consistent. Trials required data imputation where standard deviations were missing and we conducted data imputation, as guided by the Cochrane Handbook for Systematic Reviews of Intervention ${ }^{(28)}$. The majority of these studies were limited to small sample size and adopted different symptom and endoscopic scores. Clinical diversity, including variability in the agents used, dose, route, duration and the delivery methods, led to heterogeneity in the studies included in this review. We tried to overcome this risk of heterogeneity by doing a subgroup analysis where data was available but this was not possible to do in all comparisons. It is difficult to select between topical or oral steroid use in preoperative cases due to limited studies and data available for comparison. Although both mode of delivery showed better outcomes in the steroid group. Our review even though it had significant heterogeneity in some outcomes, has attempted to bring the existing evidence together and represents the best evidence on this subject available.

\section{Clinical implications of the review}

Our systematic review and meta-analysis supports the use of pre-operative corticosteroids prior to FESS. Based on current existing evidence it statistically reduces operative time and blood loss and significantly improves surgical field quality. Whether this statistical difference reflects in clinical setting remains open to debate. Studies in relation to anaesthetic outcomes in response to intra-operative corticosteroids during FESS are limited with no significant benefit in post operative pain score and rescue analgesic requirement. More studies are required to assess the benefit of corticosteroids in this respect. Postoperative use of corticosteroids following FESS is not associated with any significant improvement in symptom scores but it is associated with better endoscopic scores in CRSWNP. Use of corticosteroids was not associated with increased risk of sinusitis, which is reassuring. There was no significant difference in the recurrence risk shown in mixed population studies of CRS, CRSwNP showed favourable results towards the steroid use. However, these results need to be interpreted with caution because these studies were limited to small sample sizes and adopted different symptom and endoscopic scores and reported a small number of bleeding, infection and recurrence events.

\section{Conclusions}

Preoperative use of local and/or systemic corticosteroids in FESS, results in significantly reduced blood loss, shorter operative time and improved surgical field quality. Studies are limited on intraoperative use of corticosteroids to reduce post operative pain. There is no significant benefit seen with the use of postoperative corticosteroids following FESS in improving symptom scores. Corticosteroids improve postoperative endoscopic scores. Risk of recurrence is reduced by postoperative corticosteroids in CRSwNP although this role is unclear in CRSsNP patients. Wellconducted large RCTs are required using, standardised inclusion criteria, specified dose, duration and route of corticosteroids, validated subjective and objective outcome measures, including reporting on long term recurrence rates and complications.

\section{Key points}

- Preoperative use of local and systemic corticosteroids in FESS, results in significantly reduced blood loss, shorter operative time and improved surgical field quality.

- Studies are limited on intraoperative use of corticosteroids to reduce post operative pain.

- The limited data available do not point to significant benefit with the use of postoperative corticosteroids following FESS in improving symptom scores.

- Corticosteroids improve postoperative endoscopic scores. Risk of recurrence is reduced by postoperative corticosteroids in CRSwNP although this role is unclear in CRSsNP patients.

- Well-conducted large RCTs are required using, standardised inclusion criteria; specified dose, duration and route of corticosteroids, validated subjective and objective outcome measures, including reporting on long term recurrence rates and complications.

\section{Author contributions}

VP: Conception, planning, literature search, data extraction, analysing and writing up; JP: Literature search, data extraction, 
analysing data. GL: Data analysis; SB, PK: Data analysis and initial draft. MC, ESL, CG: Writing up and editing the draft. WJF: Conception of project, writing up and editing the draft.

\section{Conflict of interest}

ESL is funded by The Dutch Organisation for Health Research and Development (ZonMw).

\section{Conflict of interest}

Wytske Fokkens is involved in a study with a drug eluting stent (Sinuband), has performed a number of studies with (local) corticosteroids in patients with CRS sponsored by GSK and MSD.

\section{References}

1. Hastan D, Fokkens WJ, Bachert C et al. Chronic rhinosinusitis in Europe-an underestimated disease. A GA²LEN study Allergy. 2011 Sep; 66(9):1216-23.

2. Pilan RR, Pinna FR, Bezerra TF, et al. Prevalence of chronic rhinosinusitis in Sao Paulo. Rhinology. 2012 Jun; 50(2):129-38.

3. Anand VK, Epidemiology and economic impact of rhinosinusitis. Ann Otol Rhinol Laryngol Suppl. 2004 May; 193:3-5.

4. Fokkens WJ, Lund VJ, Mullol J et al. EPOS 2012: European position paper on rhinosinusitis and nasal polyps 2012. Rhinology supplement 2012; 23: 1-298

5. Aukema AAC, Fokkens WJ. Chronic rhinosinusitis: management for optimal outcomes. Treat Respire Med. 2004; 3: 97-105.

6. Scadding GK, Durham SR, Mirakian R, et al. $\mathrm{BSACl}$ guidelines for the management of rhinosinusitis and nasal polyposis. Clin Exp Allergy. 2008;38: 260-275.

7. Rimmer J, Fokkens W, Chong LY, Hopkins C. Surgical versus medical interventions for chronic rhinosinusitis with nasal polyps. Cochrane Database SystRev. 2014;12:CD006991. doi: 10.1002/14651858.

8. Kennedy DW. Pathogenesis of chronic rhinosinusitis .Ann Otol Rhinol Laryngol Suppl. 2004 May;193:6-9.

9. Poetker DM, Smith TL. Adult chronic rhinosinusitis: surgical outcomes and the role of endoscopic sinus surgery. Curr Opin Otolaryngol Head Neck Surg.2007;15:6-9.

10. Stammberger $H$. Endoscopic surgery for mycotic and chronic recurring sinusitis. Ann Otol Rhinol Laryngol.1985; 94 (suppl 119): $1-11$.

11. Kennedy DW. Functional endoscopic sinus surgery: technique.Arch Otolaryngol. 1985; 111: 643-649.

12. Jorissen M, Bachert C. Effect of corticosteroids on wound healing after endoscopic sinus surgery. Rhinology. 2009;47: 280-286,

13. Sieskiewicz A., Olszewska E., Rogowski M, Grycz E. Preoperative corticosteroid oral therapy and intraoperative bleeding during functional endoscopic sinus surgery in patients with severe nasal polyposis: a preliminary investigation. Ann Otol Rhinol Laryngol. 2006;115:7: 490-4.

14. Albu S, Gocea A, Mitre I. Preoperative treatment with topical corticoids and bleeding during primary endoscopic sinus surgery. Otolaryngol Head Neck Surg. 2010; 143:4:573-8.

15. Kabalin CS, Yarnold PR, Grammer LC. Low complication rate of corticosteroid-treated asthmatics undergoing surgical procedures. Arch Intern Med. 1995; 10; 155(13):1379-84.

16. Salerno A, Hermann R. Efficacy and safety of steroid use for postoperative pain relief Update and review of the medical literature. J Bone Joint Surg Am. 2006; 88:6:1361-72.

17. RevMan 2011 - The Nordic Cochrane Centre, The Cochrane Collaboration. Review Manager (RevMan). 5.1. Copenhagen: The Nordic Cochrane Centre, The Cochrane Collaboration, 2011.

18. Higgins JPT, Green S. (editors). Cochrane Handbook for Systematic Reviews of Interventions Version 5.1.0 [updated March 20111. The Cochrane Collaboration, 2011. Available from www.cochrane-handbook. org.

19. Clarke M., Horton R. Bringing it all together: Lancet-Cochrane collaborate on systematic reviews. Lancet .2001;357:1728.

20. Moher D, Cook DJ, Eastwood S, Olkin I, Rennie D, Stroup DF, for the QUOROM Group; Improving the quality of reports of meta-analyses of randomised controlled trials: the QUOROM statement. Lancet 1999; 354: 1896-900.

21. DerSimonian R, Laird N. Meta-analysis in clinical trials. Control Clin Trials. 1986; 7:17788

22. Mantel N., Haenszel W. Statistical aspects of the analysis of data from retrospective studies of disease. J Natl Cancer Inst.1959;22:719-748.

23. Rotenberg BW, Zhang I, Arra I, Payton KB. Postoperative care for Samter's triad patients undergoing endoscopic sinus surgery: A double-blinded, randomized controlled trial. Laryngoscope.2011; 121:12, 2702-2705

24. Cote DW, Wright ED. Triamcinoloneimpregnated nasal dressing following endoscopic sinus surgery: a randomized, double-blind, placebo-controlled study. Laryngoscope. 2010; 120:6:1269-73.

25. Lund VJ, Kennedy DW. Staging for rhinosinusitis. Otolaryngol Head Neck Surg.1997;117(3 Pt 2):S35-40.

26. Chang EH, Alandejani T, Akbari E, Ostry A, Javer A. Double-blinded, randomized, controlled trial of medicated versus nonmedicated Merocel sponges for functional endoscopic sinus surgery. Journal of Otolaryngology - Head and Neck Surgery. 2011; 40/SUPPL.1 (S14-S19).

27. Philpott $C M$, Javer $A R$, Clark A. Allergic fungal rhinosinusitis - a new staging system. Rhinology. 2011; 49(3):318-23.

28. Higgins JPT, Thompson SG. Quantifying het- erogeneity in a meta-analysis. Statist Med. 2002; 21:1539-1558.

29. Higgins JPT, Deeks JJ, Altman DG on behalf of the Cochrane Statistical Methods Group; Chapter 16: Special topics in statistics (2008) The Cochrane Collaboration. John Wiley \& Sons, Ltd "The Cochrane Book Series".

30. Hozo SP, Djulbegovic B, Hozo I. Estimating the mean and variance from the median, range, and the size of a sample. BMC Med Res Methodol.2005; 20:5:13.

31. Kang IG, Yoon BK, Jung JH, Cha HE, Kim ST. The effect of high-dose topical corticosteroid therapy on prevention of recurrent nasal polyps after revision endoscopic sinus surgery.; Am J Rhinol.2008; 22: 5:497-501.

32. Mostafa B.E. Fluticasone propionate is asociated with severe infection after endoscopic polypectomy. Arch Otolaryngol - Head Neck Surg. 1996; 122:7:729-731.

33. Forwith KD, Chandra RK, Yun PT, Miller SK, Jampel HD. A multisite trial of bioabsorbable steroid-eluting sinus implants. Citation: Laryngoscope.2011; 1/11: 2473-2480.

34. Liu Y-H, Wang QG, Shen H, et al. Clinical effect of inhalation of budesonide suspension on persistent rhino-sinusitis following endoscopic sinus surgery. Chin J New Drugs. 2008; 17/8: 688-690+692.

35. Snidvongs K, Pratt E, Chin D, Sacks R, Earls P, Harvey RJ. Corticosteroid nasal irrigations after endoscopic sinus surgery in the management of chronic rhinosinusitis.Int Forum Allergy Rhinol. 2012;2(5):415-21.

36. Lavigne F, Tulic M, Gagnon J, Hamid Q. Selective irrigation of the sinuses in the management of chronic rhinosinusitis refractory to medical therapy: a promising start. J Otolaryngology.2004; 33:1:10-6.

37. Ikram M., Abbas A., Suhail A, Onali MA, Akhtar S, lqbal M. Management of allergic fungal sinusitis with postoperative oral and nasal steroids: a controlled study. ENT J. 2009; 88/4:E8-11:1942-7522.

38. DelGaudio JM,Wise SK. Topical steroid drops for the treatment of sinus ostia stenosis in the postoperative period. Am J Rhinol. 2006; 20: 563-567.

39. Giordano J, Darras J, Chevalier D Mortuaire G.Corticothérapie préopératoire et polypose naso-sinusienne. Annales D'otolaryngologie Et De Chirurgie Cervico faciale, 2009 vol. 126, no. 3, 120-124,

40. Fraire ME, Sanchez-Vallecillo MV, Zernotti ME, Paoletti OA. Effect of premedication with systemic corticosteroids on surgical field bleeding and visibility during nasosinusal endoscopic surgery. Acta 
Otorrinolaringol Esp. 2013; 64(2):133-9.

41. Atighechi S, Azimi MR, Mirvakili SA Baradaranfar MH, Dadgarnia MH. Evaluation of intraoperative bleeding during an endoscopic surgery of nasal polyposis after a pre-operative single dose versus a 5-day course of corticosteroid. Eur Arch Otorhinolaryngol. 2013; 270(9):2451-4.

42. Dingsør G, Kramer J, Olsholt R, Søderstrøm T. Flunisolide nasal spray $0.025 \%$ in the prophylactic treatment of nasal polyposis after polypectomy. A randomized, double blind, parallel, placebo controlled study. Rhinology. 1985; 23(1):49-58.

43. Drettner B, Ebbesen A, Nilsson M. Prophylactive treatment with flunisolide after polypectomy. Rhinology. 1982; 20(3):149-58.

44. Vento SI, Blomgren K, Hytönen M, Simola M, Malmberg $\mathrm{H}$. Prevention of relapses of nasa polyposis with intranasal triamcinolone acetonide after polyp surgery: a prospective double-blind, placebo-controlled, randomised study with a 9-month follow-up. Clin Otolaryngol. 2012; 37(2):117-23.

45. Karlsson G, Rundcrantz H.A randomized trial of intranasal beclomethasone dipropionate after polypectomy. Rhinology. 1982; 20 (3):144-8.

46. Virolainen $E$, Puhakka $H$. The effect of intranasal beclomethasone dipropionate on the recurrence of nasal polyps after ethmoidectomy. Rhinology. 1980;18(1):9-18.

47. Ramadan HH. Corticosteroid therapy during endoscopic sinus surgery in children: is there a need for a second look? Arch Otolaryngol Head Neck Surg. 2001; 127(2):188-92.

48. Hong SD, Kim JH, Dhong HJ, et al. Systemic effects and safety of triamcinolone-impregnated nasal packing after endoscopic sinus surgery: a randomized, double-blinded, placebo-controlled study. Am J Rhinol Allergy. 2013; 27(5):407-10.

49. Bardaranfar MH, Ranjbar Z, Dadgarnia MH, et al. The effect of an absorbable gelatin dressing impregnated with triamcinolone within the olfactory cleft on polypoid rhinosinusitis smell disorders. Am J Rhinol Allergy. 2014; 28(2):172-5.

50. Han JK, Marple BF, Smith $T L$, et.al. Effect of steroid-releasing sinus implants on postoperative medical and surgical interventions: an efficacy meta-analysis. Int Forum Allergy Rhinol. 2012;2(4):271-9.

51. Zhao X, Grewal A, Briel M, Lee JM.A systematic review of nonabsorbable, absorbable, and steroid-impregnated spacers following endoscopic sinus surgery. Int Forum Allergy
Rhinol. 201324

52. Bross-Soriano D, Arrieta-Gomez JR, PradoCalleros H. Infections after endoscopic polypectomy using nasal steroids. Otolaryngol Head Neck Surg. 2004; 130:3:319-322.

53. Dijkstra MD, Ebbens FA, Poublon RML, Fokkens WJ. Fluticasone propionate aqueous nasal spray does not influence the recurrence rate of chronic rhinosinusitis and nasal polyps 1 year after functional endoscopic sinus surgery. Clin Exp Allergy. 2004; 34:9:1395-1400

54. Rowe-Jones JM, Medcalf M, Durham SR Richards DH, Mackay IS. Functional endoscopic sinus surgery: 5 year follow up and results of a prospective, randomised, stratified, double-blind, placebo controlled study of postoperative fluticasone propionate aqueous nasal spray. Rhinology. 2005: 43:1:2-10.

55. Wright ED, Agrawal S. Impact of perioperative systemic corticosteroids on surgical outcomes in patients with chronic rhinosinusitis with polyposis: Evaluation with the novel Perioperative Sinus Endoscopy (POSE) scoring system. Laryngoscope. 2007;117/11 SUPPL. 115:1-28.

56. Stjarne P, Olsson P, Alenius M. Use of mometasone furoate to prevent polyp relapse after endoscopic sinus surgery. Arch Otolaryngol Head Neck Surg. 2009; 135:3:296-302.

57. Ehnhage A, Olsson P, Kölbeck KG, et al. Functional endoscopic sinus surgery improved asthma symptoms as well as PEFR and olfaction in patients with nasal polyposis. Allergy. 2009; 64(5):762-9.

58. Al-Qudah M, Rashdan Y. Role of dexamethasone in reducing pain after endoscopic sinus surgery in adults: A double-blind prospective randomized trial. Ann Otol Rhinol Laryngol. 2010;119:4:266-269.

59. Murr AH, Smith TL, Hwang PH, et al. Safety and efficacy of a novel bioabsorbable, steroid-eluting sinus stent. Int Forum Allergy Rhinol. 2011;1(1):23-32.

60. Marple BF, Smith TL, Han JK et al. Advance II: a prospective, randomized study assessing safety and efficacy of bioabsorbable steroid-releasing sinus implants. Otolaryngol Head Neck Surg. 2012;146(6):1004-11.

61. Rudmik L, Mace J, Mechor B. Effect of a dexamethasone Sinu-Foam ${ }^{\text {TM }}$ middle meatal spacer on endoscopic sinus surgery outcomes: a randomized, double-blind, placebo-controlled trial. Int Forum Allergy Rhinol. 2012;2(3):248-51.

62. Jin KH, Choi JS, Kim YH, et.al. Use of Triamcinolone-Impregnated Nasal Packing
Following Endoscopic Sinus Surgery. J Rhinol. 2012;19(2):119-122.

63. Passàli D1, Bernstein JM, Passali FM, Damiani V, Passàli GC, Bellussi L.. Treatment of recurrent chronic hyperplastic sinusitis with nasal polyposis. Arch Otolaryngol Head Neck Surg. 2003;129(6):656-9.

64. Nair S, Collins M, Hung P, Rees G, Close D, Wormald PJ. The effect of betablocker premedication on the surgical field during endoscopic sinus surgery. Laryngoscope.2004; 114:6:1042-6.

65. Stammberger H, Posawetz W. Functional endoscopic sinus surgery. Concept, indications and results of the Messerklinger technique. Eur Arch Otorhinolaryngol. 1990; 247:2:63-76.

66. Levine HL. Functional endoscopic sinus surgery: evaluation, surgery, and follow-up of 250 patients.Laryngoscope. 1990;100:1:7984.

67. Kennedy DW. Prognostic factors, outcomes and staging in ethmoid sinus surgery. Laryngoscope. 1992; 102 (12 Pt 2 Suppl 57), $1-18$.

68. Ullian ME. The role of corticosteroids in the regulation of vascular tone. Cardiovasc Res. 1999; 41 (1):55-64.

69. Kemppainen TP, Tuomilehto H, Kokki H, Seppä J, Nuutinen J. Pain treatment and recovery after endoscopic sinus surgery. Laryngoscope. 2007; 17:8:1434-8.

70. Rudmik L, Soler ZM, Orlandi RR, et al Early postoperative care following endoscopic sinus surgery: an evidence-based review with recommendations. Int Forum Allergy Rhinol. 2011; 1:6:417-30.

71. Snidvongs K, Kalish L, Sacks R, Craig JC, Harvey RJ. Topical corticosteroids for chronic rhinosinusitis without polyps. Cochrane Database Syst Rev.2011;10;(8): CD009274.

\section{Vishal Pundir}

Fellow Rhinology and Skull Base

Surgery

Academic Medical Centre

Meibergdreef 9

1105 AZ Amsterdam

The Netherlands

E-mail: vishalpundir@yahoo.com

Tel: +44-795-667 2723 